\title{
Regulatory $T$ cells in the treatment of disease
}

\author{
Amir Sharabi ${ }^{1,2 *}$, Maria G. Tsokos ${ }^{1}$, Ying Ding ${ }^{3}$, Thomas R. Malek ${ }^{3}$, \\ David Klatzmann ${ }^{4,5,6 *}$ and George C. Tsokos ${ }^{1 *}$
}

\begin{abstract}
Regulatory $T\left(\mathrm{~T}_{\text {reg }}\right)$ cells suppress inflammation and regulate immune system activity. In patients with systemic or organ-specific autoimmune diseases or those receiving transplanted organs, $\mathrm{T}_{\text {reg }}$ cells are compromised. Approaches to strengthen $\mathrm{T}_{\text {reg }}$ cell function, either by expanding them ex vivo and reinfusing them or by increasing the number or capacity of existing $\mathrm{T}_{\text {reg }}$ cells, have entered clinical trials. Unlike the situation in autoimmunity, in patients with cancer, $\mathrm{T}_{\text {reg }}$ cells limit the antitumour immune response and promote angiogenesis and tumour growth. Their immunosuppressive function may, in part, explain the failure of many immunotherapies in cancer. Strategies to reduce the function and/or number of $T_{\text {reg }}$ cells specifically in tumour sites are being investigated to promote antitumour immunity and regression. Here, we describe the current progress in modulating $\mathrm{T}_{\text {reg }}$ cells in autoimmune disorders, transplantation and cancer.
\end{abstract}

'Department of Medicine, Beth Israel Deaconess Medical Center, Harvard Medical School, Boston, MA, USA. ${ }^{2}$ Sackler Faculty of Medicine, Tel-Aviv University, Tel-Aviv, Israel.

${ }^{3}$ Department of Microbiology and Immunology, The Diabetes Research Institute, Miller School of Medicine, University of Miami, Miami, FL, USA. ${ }^{4}$ Sorbonne Université, UPMC Univ Paris 06, UMRS 959, ImmunologyImmunopathologyImmunotherapy (i3), Paris, France. IINSERM, UMRS 959, ImmunologyImmunopathologyImmunotherapy (i3), Paris, France. ${ }^{6}$ Assistance Publique Hôpitaux de Paris, Hôpital Pitié-Salpêtrière, Biotherapy and Département HospitaloUniversitaire InflammationImmunopathology-Biotherapy (i2B), Paris, France.

*e-mail: isharabiamir@gmail.com; david.klatzmann@upmc.fr; gtsokos@bidmc.harvard.edu
The immune system employs numerous mechanisms to regulate $\mathrm{T}$ cell-dependent immune responses. Downregulation of an immune response following infection is critical to avoid uncontrolled clonal expansion and excessive cytokine production, and reducing the immune response to self-antigens is necessary to prevent organ damage in autoimmune diseases. On the flip side, the suppression of the immune response that occurs in patients with cancer is detrimental, as it allows unchecked tumour growth.

Much of our understanding of these processes comes from uncovering the cellular and molecular mechanisms by which responses to self-antigens are regulated. Numerous different cells harbour suppressive activity that contributes to self-tolerance (Supplementary Box 1). The most important cells in the suppression of self-reactive $\mathrm{T}$ cells are the $\mathrm{CD} 4^{+} \mathrm{T}$ cells that express forkhead box P3 (FOXP3) (herein referred to as regulatory $\mathrm{T}\left(\mathrm{T}_{\text {reg }}\right)$ cells). The critical role of $\mathrm{T}_{\text {reg }}$ cells in the development of autoimmunity has been highlighted by the multi-organ autoinflammatory syndrome that develops in FOXP3-deficient mice ${ }^{1,2}$ and the immune dysregulation, polyendocrinopathy, enteropathy, X-linked (IPEX) syndrome seen in humans $s^{3,4}$, which occurs in individuals who harbour mutations in FOXP3.

Approaches to increase the number and function of $\mathrm{T}_{\text {reg }}$ cells could clearly benefit patients with autoimmune disorders. Some of these approaches are now in clinical trials. One such effort involves adoptive $\mathrm{T}_{\text {reg }}$ cell therapy ${ }^{5-7}$ and includes the potential to engineer antigen specificity into the transferred $\mathrm{T}_{\text {reg }}$ cells; in another, low-dose interleukin (IL)-2 is administered to selectively expand $\mathrm{T}_{\text {reg }}$ cell populations, a strategy that could be applied to many patients with autoimmune diseases ${ }^{8-10}$. In addition, strategies to reduce the function and/or number of $\mathrm{T}_{\text {reg }}$ cells are being investigated to promote antitumour immunity.

In this Review, we focus on therapies that target $\mathrm{T}_{\text {reg }}$ cells and are now being exploited to treat autoimmune diseases and cancer. We discuss the biology and function of $\mathrm{T}_{\text {reg }}$ cells and then highlight the current therapeutic approaches being investigated to either empower them or limit their suppressive capacity and expansion.

\section{Biology of $\mathrm{T}_{\text {reg }}$ cells \\ Developmental heterogeneity}

$\mathrm{T}_{\text {reg }}$ cells are marked by the transcriptional regulator FOXP3 and constitute approximately $5-10 \%$ of peripheral $\mathrm{CD}^{+} \mathrm{T}$ cells in humans and mice ${ }^{11}$. FOXP3 is a reliable marker for mouse $\mathrm{T}_{\text {reg }}$ cells. Even though FOXP3 is an intracellular protein, genetic reporter mice have facilitated rigorous purification of viable $\mathrm{T}_{\text {reg }}$ cells for molecular and cellular analysis. In humans, $\mathrm{T}_{\text {reg }}$ cells are characterized by constitutive expression of the transcription factor FOXP3, high expression of the low-avidity IL-2 receptor (IL-2R) a chain (CD25) and low levels of the IL-7R $\alpha$-chain (CD127) ${ }^{12,13}$ (Supplementary Box 1). However, FOXP3 is a less reliable marker for the identification of $\mathrm{T}_{\text {reg }}$ cells in humans because some activated effector $\mathrm{T}$ cells ( $\mathrm{T}_{\text {eff }}$ cells) also express this molecule, albeit transiently and often at a somewhat low level ${ }^{14-16}$. 
Self-tolerance

The inability to respond to

self-antigens.

$\mathrm{CD}^{+}{ }^{+} \mathrm{T}$ cells

$T$ cells that recognize peptides presented by major histocompatibility complex class II molecules and provide help to $B$ cells to produce antibodies or to $\mathrm{CD}^{+}{ }^{+}$cells to produce cytotoxic responses.

Effector T cells

( $\mathrm{T}_{\text {eff }}$ cells). Short-lived activated cells that defend the body in

an immune response.

T helper 1 cells

( $T_{H} 1$ cells). Cells that produce interleukin 2 , interferon- $\gamma$ and tumour necrosis factor and are pro-inflammatory.

T helper 17 cells

$\left(\mathrm{T}_{\mathrm{H}} 17\right.$ cells). Cells that produce interleukin-17 and play an

important role in maintaining mucosal barriers and

contributing to pathogen clearance at mucosal surfaces; they also propagate autoimmune and inflammatory pathology.

Co-stimulatory molecule A membrane-bound or secreted product that is required for co-stimulation. This second signal (in addition to $T$ cell receptor engagement) from an antigen-presenting cell to a $\mathrm{T}$ cell allows the $\mathrm{T}$ cell to become activated and produce cytokines. CD28 (on T cells) is the best known example.

Antigen-presenting cells (APCs). Cells that display antigen complexed with major histocompatibility complex molecules on their surfaces, which they present to T cells.

Dendritic cells

(DCs). Cells that are named for their surface projections (which resemble the dendrites of neurons). They continuously sample the environment for antigen, which they process and present to T cells.

$\mathrm{CD}^{+}+\mathrm{T}$ cells Cytotoxic $T$ cells that recognize peptides presented by major histocompatibility complex class I molecules.
FOXP3 controls many functions of $\mathrm{T}_{\text {reg }}$ cells. FOXP3 stabilizes the $\mathrm{T}_{\text {reg }}$ cell lineage in part by reinforcing a gene expression programme that is required for the suppressive function of $\mathrm{T}_{\text {reg }}$ cells $\mathrm{s}^{2,17,18}$. $\mathrm{T}_{\text {reg }}$ cell populations expand in response to IL-2, and this cytokine is required for $\mathrm{T}_{\text {reg }}$ cell survival. FOXP3 represses IL-2 expression, which is produced by $\mathrm{T}_{\text {eff }}$ cells during immune reactions, and, thus, $\mathrm{T}_{\text {reg }}$ cells are dependent on paracrine IL-2.

$\mathrm{T}_{\text {reg }}$ cells are classified into two major groups on the basis of their developmental origins. One population of $\mathrm{T}_{\text {reg }}$ cells, designated thymus-derived $\mathrm{T}_{\text {reg }}\left(\mathrm{tT}_{\mathrm{reg}}\right)$ cells, develops in the thymus. Another population of $\mathrm{T}_{\text {reg }}$ cells develops when conventional peripheral $\mathrm{CD} 4^{+}$ $\mathrm{T}$ cells become activated by antigen and encounter certain environmental signals that promote FOXP3 expression and suppressive function. When this occurs in vitro, these $\mathrm{T}_{\text {reg }}$ cells are designated induced $\mathrm{T}_{\text {reg }}\left(\mathrm{iT}_{\text {reg }}\right)$ cells, and when this occurs in vivo, these cells are designated peripherally induced $\mathrm{T}_{\mathrm{reg}}\left(\mathrm{pT}_{\mathrm{reg}}\right)$ cells (Supplementary Box 2; Supplementary Fig. 1).

Unlike $\mathrm{tT}_{\text {reg }}$ cells, which constitute a stable population of suppressor cells, $\mathrm{pT}_{\text {reg }}$ cells have substantial plasticity and may convert into $\mathrm{T}_{\text {eff }}$ cells, which are characterized by the production of interferon- $\gamma$ (IFN $\gamma)$ and IL-17. This feature allows for a cellular response that adapts to conditions within specific tissue sites. For example, $\mathrm{pT}_{\text {res }}$ cells are abundant in the gut mucosa, where they promote tolerance to a normal microbiota. However, during an infection, the inflammatory environment may convert $\mathrm{pT}_{\text {reg }}$ cells into $\mathrm{T}$ helper 1 cells $\left(\mathrm{T}_{\mathrm{H}} 1\right.$ cells) or $\mathrm{T}$ helper 17 cells $\left(\mathrm{T}_{\mathrm{H}} 17\right.$ cells $)$ to promote an immune response ${ }^{19}$.

A two-step model has been proposed whereby signalling from the T cell receptor (TCR), the co-stimulatory molecule CD28 and IL-2R promotes $\mathrm{t}_{\text {reg }}$ cell development $^{20}$ (FIG. 1). The first step depends on the engagement of TCR and CD28, which together define archetypal immune stimulation, whereby TCRs with high affinity for self-antigens interact with self-peptide-major histocompatibility complex (MHC) class II complexes on antigen-presenting cells (APCs) to initiate fairly strong TCR signalling that activates nuclear factor- $\kappa \mathrm{B}$ $(\mathrm{NF}-\kappa \mathrm{B})$, nuclear factor of activated T cells (NFAT) and forkhead box protein $\mathrm{O}$ (FOXO) transcription factors in $\mathrm{CD}^{+} \mathrm{CD}^{-}$thymocytes $^{21-23}$. NFAT and FOXO bind directly to the promoter, conserved non-coding region 2 (CNS2) and CNS3 of the FOXP3 gene to drive FOXP3 expression and $\mathrm{T}_{\text {reg }}$ cell development ${ }^{18,24,25}$. These cells then differentiate into IL-2-responsive $\mathrm{T}_{\text {reg }}$ cell progenitors $\left(\mathrm{CD} 4^{+} \mathrm{CD} 25^{+} \mathrm{CD} 122^{\text {high }} \mathrm{GITR}^{\text {high }} \mathrm{FOXP} 3^{-} \mathrm{T}\right.$ cells). In the second step, IL-2R signalling promotes these FOXP3- $\mathrm{T}_{\text {reg }}$ cell progenitors to further develop into fully functional mature $\mathrm{FOXP} 3^{+} \mathrm{T}_{\text {reg }}$ cells by activation of signal transducer and activator of transcription 5

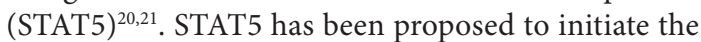
demethylation of CNS2, which would help facilitate FOXP3 transcription.

In addition to these primary signalling events, other molecules promote $\mathrm{t}_{\mathrm{reg}}$ cell maturation. Some of these include TNF receptor superfamily (TNFRSF) members, such as GITR (also known as TNFRSF18), OX40 (also known as TNFRSF4) and TNFR2 (also known as
TNFRSF1B), which function as co-stimulatory molecules to sensitize $\mathrm{T}_{\text {reg }}$ cell precursors to IL-2 stimulation ${ }^{26}$. Another important aspect of $\mathrm{tT}_{\text {reg }}$ cell development is that the phosphoinositide 3-kinase (PI3K) pathway, which mediates signalling downstream of the TCR, is attenuated in $\mathrm{T}_{\text {reg }}$ cells relative to $\mathrm{T}_{\text {eff }}$ cells owing to the upregulation of PTEN in $\mathrm{T}_{\text {reg }}$ cells; PTEN is the main negative regulator of the PI3K pathway ${ }^{27}$. Whereas transforming growth factor $\beta$ (TGF $\beta$ ) is essential for $\mathrm{pT}_{\text {reg }}$ cell development, its role in $\mathrm{tT}_{\text {reg }}$ cell development is less clear, as mice lacking TGF $\beta$ signalling did not have a numerical defect in $\mathrm{tT}_{\text {reg }}$ cells ${ }^{28}$. Other studies, however, suggest that TGF $\beta$, stimulated by thymic apoptosis, is an essential factor for Foxp 3 transcription and $\mathrm{tT}_{\text {reg }}$ cell generation in the thymus ${ }^{29-31}$.

\section{Functions and phenotypic heterogeneity}

Multiple mechanisms have been ascribed to mouse and human $\mathrm{T}_{\text {reg }}$ cells that suppress autoreactive $\mathrm{T}$ cells. One prominent mechanism is the secretion of proteins, such as IL-10, IL-35 and TGF $\beta$, which suppress pro-inflammatory responses. $\mathrm{T}_{\text {reg }}$ cells also promote the conversion of dendritic cells (DCs) to a tolerogenic state through surface expression of cytotoxic T lymphocyte protein 4 (CTLA 4$)^{32,33}$, which down-modulates the expression of the co-stimulatory molecules CD80 and CD86 on APCs and stimulates DCs to produce the immunosuppressive enzyme indoleamine 2,3-dioxygenase (IDO). Lymphocyte activation gene 3 (LAG3), an immune checkpoint receptor, and neuropilin 1 (NRP1) have also been suggested to promote tolerogenic $\mathrm{DCs}^{34,35}$. In turn, DCs, particularly those chronically exposed to antigen and rendered tolerogenic, may promote $\mathrm{T}_{\text {reg }}$ cell expansion and function (see below).

The ectoenzymes CD39 and CD73 are highly expressed on the surface of some $\mathrm{T}_{\text {reg }}$ cells and these two enzymes together convert extracellular ATP to adenosine $e^{36,37}$, which inhibits the proliferation of $\mathrm{T}_{\text {eff }}$ cells and suppresses the function of $\mathrm{DCs}^{38}$. In addition, the high level of CD25 on $\mathrm{T}_{\text {reg }}$ cells sequesters IL-2 within the microenvironment and therefore hampers IL-2-dependent activation of CD8 ${ }^{+} T$ cells and natural killer (NK) cells ${ }^{39-41}$. Lastly, intratumoural $\mathrm{T}_{\text {reg }}$ cells also exhibit direct cytotoxicity towards NK cells and autoreactive $\mathrm{CD}^{+} \mathrm{T}$ cells, which mediate tumour cell clearance ${ }^{42,43}$.

Two main subsets of mature $\mathrm{T}_{\text {reg }}$ cells have been defined on the basis of distinctive phenotypes and gene expression. These are resting or naive $\mathrm{T}_{\text {reg }}\left(\mathrm{nT}_{\text {reg }}\right)$ cells and activated or effector $\mathrm{T}_{\text {reg }}\left(\mathrm{eT}_{\text {reg }}\right)$ cells, including tissueresident $\mathrm{T}_{\text {reg }}$ cells (BOX 1). $\mathrm{e}_{\text {reg }}$ cells differ critically from $\mathrm{nT}_{\text {reg }}$ cells in that the former often express increased levels of immunosuppressive molecules, particularly IL-10, and have increased surface expression of tissue-seeking chemokine receptors ${ }^{44}$. This property, in conjunction with downregulation of CC-chemokine receptor 7 (CCR7) and L-selectin (also known as CD62L; these two protein are markers of naive cells), promotes the migration of highly functional $\mathrm{T}_{\text {reg }}$ cells into tissues ${ }^{45}$. TCR repertoire analysis has shown numerous major clonotype expansions in $\mathrm{eT}_{\text {reg }}$ cells from deep tissue draining lymph nodes; these clonotypes are absent or reduced in activated 
a Thymic $T_{\text {reg }}$ cells
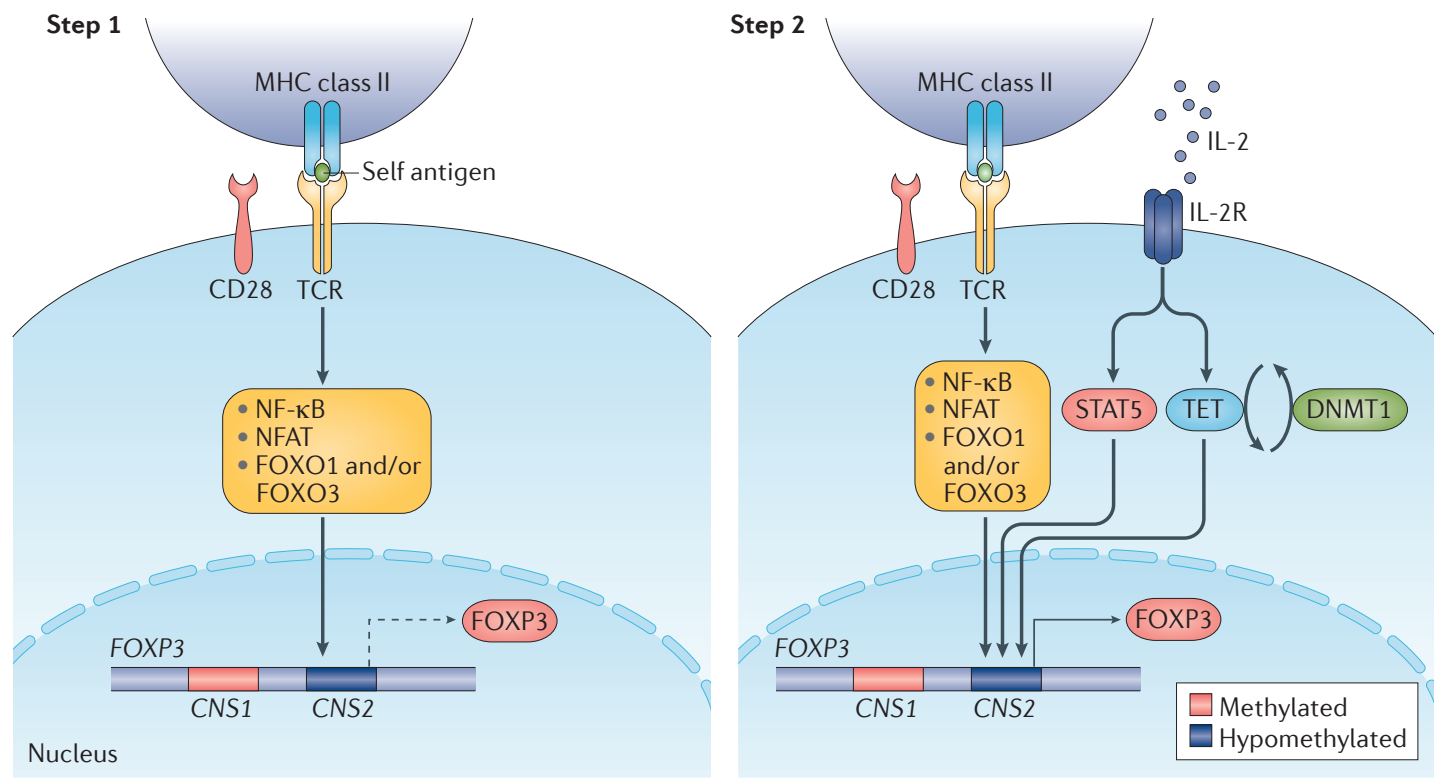

b Peripherally induced $T_{\text {reg }}$ cells

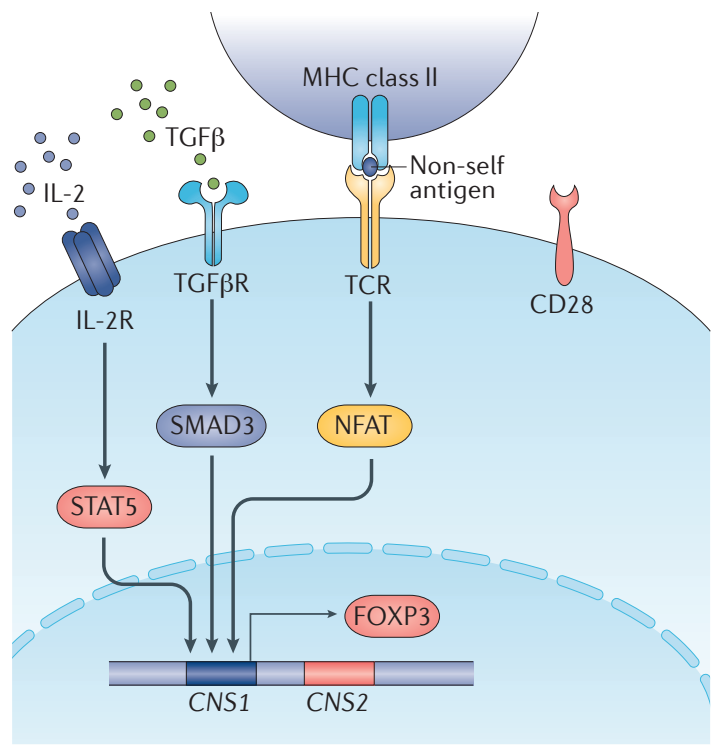

c Induced $\mathrm{T}_{\text {reg }}$ cells (in vitro)

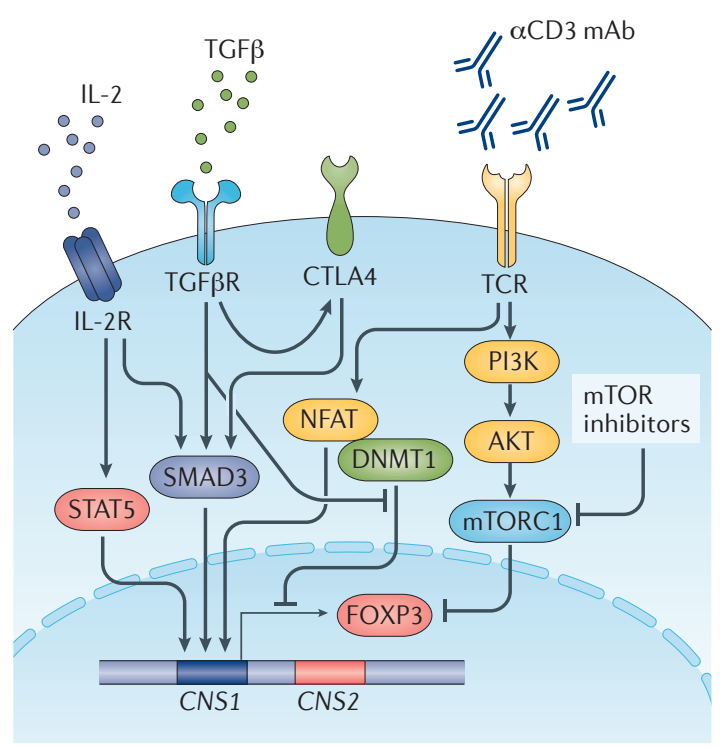

Figure 1 | Steps in $\mathrm{T}_{\text {reg }}$ cell development in vivo and in vitro. a $\mid$ The development of regulatory $T\left(\mathrm{~T}_{\text {reg }}\right)$ cells in the thymus occurs in steps and requires the expression of the T cell receptor (TCR) followed by the expression of the interleukin 2 receptor (IL-2R). When the TCR and self-antigens interact at a moderate level of avidity (just below the threshold for negative selection), the $\alpha$-chain of IL-2R (CD25) is expressed and accumulates on the cell surface; IL-2 then plays a central role in $\mathrm{T}_{\text {reg }}$ cell development independently of the TCR. The expression of forkhead box P3 (FOXP3) increases following the TCR-self-peptide-major histocompatibility complex (MHC) interaction. Transcription factors downstream of TCR engagement become activated and bind to the gene promoter and conserved non-coding region 2 (CNS2) of FOXP3. The expression of FOXP3 is maintained in IL-2-responsive $\mathrm{T}_{\text {reg }}$ cells. Signalling through IL-2R preserves the hypomethylated status of CNS2 by recruiting TET. IL-2R signalling also activates signal transducer and activator of transcription 5 (STAT5) to further increase FOXP3 expression. $\mathbf{b} \mid \mathrm{T}_{\text {reg }}$ cells that are generated in vivo outside the thymus arise from naive $\mathrm{CD} 4^{+} \mathrm{T}$ cells

Natural killer (NK) cells Cytotoxic lymphocytes critical to the innate immune system that provide rapid responses to viral infection and respond to tumour formation. They express an array of activating and inhibitory receptors and produce interferon- $\gamma$. in response to transforming growth factor- $\beta$ (TGF $\beta$ ) and IL- 2 in peripheral tissues. The expression of FOXP3 in these cells derives mainly from TCR interactions with non-self-antigen-MHC and IL-2R signalling, which affect CNS1, with minor contributions from TGF $\beta$ signalling. $\mathrm{c} \mid$ FOXP3 expression in in vitro-induced $\mathrm{T}_{\text {reg }}\left(\mathrm{iT}_{\text {reg }}\right)$ cells is activation-dependent and short-lived. The addition of TGF $\beta$ or IL-2 to the media results in CNS1 hypomethylation, as DNA (cytosine-5)methyltransferase 1 (DNMT1) is excluded from the nucleus. Both cytokines activate SMAD3 and STAT5, which increase FOXP3 expression. Mechanistic or mammalian target of rapamycin (mTOR) inhibitors may contribute to the activation of $\mathrm{T}_{\text {reg }}$ cells in vitro. The CNS2 in $\mathrm{iT}_{\text {reg }}$ cells is only partially hypomethylated, and therefore, FOXP3 expression is somewhat unstable. CTLA4, cytotoxic T lymphocyte protein 4; mAb, monoclonal antibody; mTORC1, mTOR complex 1; NF-KB, nuclear factor-KB; NFAT, nuclear factor of activated T cells; PI3K, phosphoinositide 3-kinase. 


\section{Box $1 \mid$ Tissue-resident $T_{\text {reg }}$ cells}

Regulatory $T\left(T_{\text {reg }}\right)$ cells constitute a higher percentage of the $T$ cells present in tissues than in the peripheral blood, and most of the tissue-resident $\mathrm{T}_{\text {reg }}$ cells have an effector or memory phenotype ${ }^{299}$ and could be classified as effector $\mathrm{T}_{\text {reg }}$ cells. Moreover, gene expression patterns in tissue-resident $\mathrm{T}_{\text {reg }}$ cells are distinctly dependent on the hosting tissue. For example, an intestinal peripherally induced $\mathrm{T}_{\text {reg }}$ cell subset expresses ROR $\gamma \mathrm{t}$ and can produce interleukin (IL)-17 (REF. ${ }^{300}$ ). These two molecules are hallmarks of T helper 17 cells, which are present in large numbers in the intestine. Similarly, visceral adipose tissue $T_{\text {reg }}$ cells express peroxisome proliferator-activated receptor- $\gamma$ to regulate insulin sensitivity ${ }^{301,302}$. Visceral adipose tissue $\mathrm{T}_{\text {reg }}$ cells also express high levels of the IL-33 receptor (IL-33R; also known as IL1RL1), which is required for their accumulation in visceral adipose tissue ${ }^{303}$. Some strains of gut microorganisms can induce $\mathrm{T}_{\text {reg }}$ cells in the intestine ${ }^{304}$. Deletion of skin-resident $\mathrm{T}_{\text {reg }}$ cells in mice leads to atopic dermatitis ${ }^{305}$. The biology and characteristics of human tissue-resident $\mathrm{T}_{\text {reg }}$ cells have been reviewed ${ }^{306,307}$.

T helper 2 cells

$\left(T_{H} 2\right.$ cells). They promote allergic responses and provide help to B cells. Cells that can also promote resolution of inflammation and produce interleukin 4 (IL-4), IL-5, IL-6 and IL-10.

T follicular helper cells ( $T_{F H}$ cells). Antigen-experienced $\mathrm{CD} 4{ }^{+} \mathrm{T}$ cells found in the periphery within $\mathrm{B}$ cell follicles of secondary lymphoid organs such as lymph nodes, spleens and Peyer's patches. memory $\mathrm{T}_{\text {reg }}$ cells from superficial lymph nodes and in $\mathrm{nT}_{\text {reg }}$ cell populations, further suggesting that $\mathrm{e}_{\text {reg }}$ cells actively control autoimmunity ${ }^{46}$. Thus, $\mathrm{eT}_{\text {reg }}$ cells exhibit characteristics important for re-establishing tolerance in autoimmune-inflamed tissues. Correspondingly, $\mathrm{T}_{\text {reg }}$ cell-based therapies that promote $\mathrm{eT}_{\text {reg }}$ cells are likely to be more efficacious in tissues that are undergoing an immune or autoimmune attack $^{47}$.

In many ways, the heterogeneity of $\mathrm{T}_{\text {reg }}$ cells mirrors that reported for $\mathrm{T}_{\mathrm{H}}$ cells, and one might simply view $\mathrm{T}_{\mathrm{reg}}$ cells as activated $\mathrm{T}$ cells that suppress rather than promote immunity. An important parallel between $\mathrm{T}_{\text {reg }}$ cells and $\mathrm{T}_{\mathrm{H}}$ cells is that key transcriptional regulators that are expressed in $\mathrm{T}_{\mathrm{H}}$ cells are also expressed by $\mathrm{T}_{\text {reg }}$ cells and are associated with the suppression of the corresponding $\mathrm{T}_{\mathrm{H}}$ cell subset. For example, $\mathrm{T}_{\text {reg }}$ cells that suppress $\mathrm{T}_{\mathrm{H}} 1$ cells express T-BET (also known as T-box transcription factor TBX21), the signature transcription factor of $\mathrm{T}_{\mathrm{H}} 1 \mathrm{cells}^{48}$. Likewise, $T_{\text {reg }}$ cells that suppress $T$ helper 2 cells $\left(\mathrm{T}_{\mathrm{H}} 2\right.$ cells), $\mathrm{T}_{\mathrm{H}} 17$ cells and $\mathrm{T}$ follicular helper cells ( $\mathrm{T}_{\mathrm{HH}}$ cells) express GATA3, STAT3, and BCL6, respectively, which are key transcriptional regulators associated with each of these $\mathrm{T}_{\mathrm{H}}$ subset $^{49-51}$. The precise mechanism of how $\mathrm{T}_{\text {reg }}$ cell subsets affect a particular type of $\mathrm{T}_{\mathrm{H}}$ cell response is not well understood. However, it is likely that both $\mathrm{T}_{\text {reg }}$ cells and $\mathrm{T}_{\mathrm{H}}$ cells respond to similar environmental cues, which promote $\mathrm{T}_{\text {reg }}$ cells to migrate to and counteract inflammatory responses promoted by the corresponding $\mathrm{T}_{\mathrm{H}}$ cell subset, thus preventing undesired bystander suppression ${ }^{52}$.

\section{TCR and IL-2R signalling}

$\mathrm{T}_{\text {reg }}$ cell homeostasis in the periphery depends critically on TCR and IL-2R signals. In mice with conditional $\mathrm{TCR}$ ablation in $\mathrm{T}_{\text {reg }}$ cells, $\mathrm{nT}_{\text {reg }}$ cell numbers were readily maintained, whereas $\mathrm{eT}_{\text {reg }}$ cell numbers were substantially reduced ${ }^{53}$. Thus, maintenance of the $\mathrm{eT}_{\text {reg }}$ cell population depends on recent TCR stimulation. In addition, when placed in competitive, IL-2-limited environments, $\mathrm{T}_{\text {reg }}$ cells that have intrinsically impaired IL-2R signalling compete poorly with wild-type $\mathrm{T}_{\text {reg }}$ cells, showing clearly that IL-2 is important for their maintenance in secondary lymphoid tissues ${ }^{45}$. Recently IL-2-activated $\mathrm{T}_{\text {reg }}$ cells in vivo, defined as those $\mathrm{T}_{\text {reg }}$ cells that contain activated STAT5, are $\mathrm{nT}_{\text {reg }}$ cells, indicating that this $\mathrm{T}_{\text {reg }}$ cell subset is especially dependent on IL-2 for maintenance ${ }^{45,54}$. IL-2 also promotes e $\mathrm{T}_{\text {reg }}$ cell survival, as terminally differentiated $\left(\mathrm{KLRG1}^{+}\right) \mathrm{eT}_{\mathrm{reg}}$ cell numbers are reduced in mice with intrinsic defects in IL-2R signalling ${ }^{55}$. IL-2 promotes $\mathrm{T}_{\text {reg }}$ cell survival in part by upregulating the transcription of the anti-apoptotic molecules BCL2 and MCL1 (REF.56).

Administration of IL-2 to mice (alone or as an IL-2anti-IL-2 antibody complex to increase its bioavailability) promotes the proliferation of $\mathrm{T}_{\mathrm{reg}}$ cells in the periphery. This indicates that IL-2 is a potent growth factor for $\mathrm{T}_{\mathrm{reg}}$ cells and raises the possibility that it can be used as a means to directly expand these suppressive cells in the context of autoimmune diseases. The conundrum had been that IL-2 is well known to be a growth factor for $\mathrm{T}_{\text {eff }}$ cells as well. Thus, the use of IL-2 in autoimmune diseases was thought to be contraindicated because IL-2 might also expand pathogenic self-reactive T cells. However, studies of genetically modified mice in which IL-2R signalling was impaired, but not abrogated, showed that low IL-2R signalling readily promoted the development and homeostasis of $\mathrm{T}_{\text {reg }}$ cells while the IL-2-dependent activation of $\mathrm{T}_{\text {eff }}$ cells remained impaired ${ }^{57,58}$. The high level of expression of CD25 on mouse and human $\mathrm{T}_{\text {reg }}$ cells, relative to other lymphoid cells, is one key reason why $\mathrm{T}_{\text {reg }}$ cells exhibit high sensitivity to low levels of IL-2. This was used to conceptualize the first investigation of IL-2 in the context of autoimmune diseases ${ }^{9,10}$ and will be discussed in more detail below, as these approaches are in clinical trials.

\section{Key molecules that control $T_{\text {reg }}$ cells}

The list of molecules, including transcription factors, kinases and phosphatases, that are recognized to be important for the function of $\mathrm{T}_{\text {reg }}$ cells is growing. These molecules offer additional targets for therapeutic exploitation.

Mechanistic target of rapamycin (mTOR) integrates cell signalling pathways and metabolic inputs and enables specific cell responses. mTOR is a serine/threonineprotein kinase in the PI3K-related kinase family that forms the catalytic subunit of two distinct protein complexes, known as mTOR complex 1 (mTORC1) and mTORC2. mTORC2 phosphorylates and activates AKT, a key effector of PI3K signalling that promotes cell survival, proliferation and growth through the phosphorylation and inhibition of several key substrates, which include transcription factors and kinases ${ }^{59}$.

In $\mathrm{T}_{\text {eff }}$ cells, mTOR signalling is high and increases the inflammatory response; mTOR activity is low in $\mathrm{T}_{\text {reg }}$ cells $^{60}$. Indeed, deletion of mTOR in all conventional $\mathrm{CD} 4^{+} \mathrm{T}$ cells results in a phenotype reminiscent of $\mathrm{T}_{\text {reg }}$ cells $s^{61}$. However, a certain level of mTORC1 activity is necessary for $\mathrm{T}_{\text {reg }}$ cells to meet their metabolic demands, which occurs through cholesterol and lipid metabolism, specifically through the mevalonate pathway ${ }^{62}$. mTORC1 is essential to $\mathrm{T}_{\text {reg }}$ cell function, and when mTORC1 is conditionally knocked out in $\mathrm{T}_{\text {reg }}$ cells, mice develop a severe lymphoproliferative autoimmune condition ${ }^{62}$. In $\mathrm{T}_{\text {eff }}$ cells, mTOR upregulates genes associated with the pentose phosphate pathway and the glucose transporter 
GLUT1 (also known as SLC2A1), thereby facilitating glucose entry into the cells and subsequent glycolysis. By contrast, in $\mathrm{T}_{\text {reg }}$ cells, in a manner similar to that observed in memory CD8 ${ }^{+}$cells, mTOR is required not for glycolysis but rather for lipogenesis to maintain the functional capacity of these cells ${ }^{63,64}$. These findings illustrate how mTORC1 integrates signalling from the TCR, IL-2 and nutrient availability to modulate lipogenic pathways that are essential for $\mathrm{T}_{\text {reg }}$ cell function. Thus, although complete deletion of mTORC1 results in $\mathrm{T}_{\text {reg }}$ cell dysfunction and autoimmunity, unrestrained mTORC1 activity also disrupts $\mathrm{T}_{\text {reg }}$ cell homeostasis.

PTEN is a lipid phosphatase that negatively regulates PI3K by dephosphorylating phosphatidylinositol $(3,4,5)$-triphosphate (PIP3), the dominant signalling molecule produced by the kinase activity of PI $3 \mathrm{~K}^{65}$. PIP3 is highly expressed in $\mathrm{T}_{\text {reg }}$ cells and regulates their differentiation $^{66}$. It has been shown that the NRP1-semaphorin $4 \mathrm{~A}$ (SEMA4A) axis stabilizes $\mathrm{T}_{\text {reg }}$ cell function by restraining PI3K and potentiating PTEN activity ${ }^{67}$. Conditional deletion of PTEN in $\mathrm{T}_{\text {reg }}$ cells in mice resulted in a systemic lymphoproliferative autoimmunity that resembled systemic lupus erythematosus (SLE) with high titres of anti-nuclear antibodies and immune complex glomerulonephritis. Mechanistically, all these changes were attributed to increased mTORC2 and AKT activity ${ }^{27}$.

Protein phosphatase 2A (PP2A), a serine/threonine phosphatase, is crucial for $\mathrm{T}_{\text {reg }}$ cell function. In mice, the catalytic activity of PP2A in $\mathrm{T}_{\text {reg }}$ cells is substantially higher than in conventional $\mathrm{T}$ cells, and conditional deletion of PP2A in $\mathrm{T}_{\text {reg }}$ cells leads to severe multi-organ autoimmune pathology. FOXP3 promotes the generation of ceramide, which activates the catalytic subunit of PP2A, which in turn inactivates mTORC1 but not mTORC2 (REF. ${ }^{68}$ ).

Other molecules, such as NOTCH, other transcription factors and chromatin remodellers (Supplementary $\underline{B o x} 3$ ), are also key to $\mathrm{T}_{\text {reg }}$ cell function. Understanding the molecular and/or biochemical events that govern $\mathrm{T}_{\text {reg }}$ cell function is vital to the development of new $\mathrm{T}_{\text {reg }}$ cellbased therapeutic approaches. Manipulation of kinase or phosphatase activity, preferably in a cell-specific manner, may offer, as discussed below, opportunities to modulate inflammatory and autoinflammatory responses.

\section{$\mathbf{T}_{\text {reg }}$ cells in key human diseases \\ Monogenic diseases}

Several monogenic conditions illustrate the importance of functioning $\mathrm{T}_{\text {reg }}$ cells to human immune homeostasis. The prototypical example is FOXP3 deficiency, which results in IPEX syndrome, a disease that appears within the first several years of life in males and requires bone marrow transplantation ${ }^{4,69}$.

Patients with CD25 deficiency present with both autoimmunity and immunodeficiency and a disease that is clinically similar to IPEX syndrome. CD25 deficiency does not affect the number of FOXP3 ${ }^{+}$cells in the circulation but impairs their suppressive function by decreasing IL-10 production and increasing IL-2 availability (loss of the 'IL-2 sink') ${ }^{70,71}$. Deficiency of or mutations in STAT5B $B^{72,73}$, CTLA4 $\left(\mathrm{REF}^{74}\right)$ or $L R B A^{75}$ also result in autoimmune phenotypes.

\section{Systemic lupus erythematosus}

$\mathrm{T}_{\text {reg }}$ cells have been logically implicated in the pathophysiology of systemic autoimmune diseases, although their numbers and function have been reported to be variable $^{76}$. This variability most likely reflects the heterogeneity of the disease and the small size of the studied cohorts. The clinical heterogeneity is confounded by diversity in experimental protocols, markers to identify $\mathrm{T}_{\text {reg }}$ cells and the conditions and performance of functional assays ${ }^{76-79}$. The proportion of activated $\mathrm{T}_{\mathrm{reg}}$ cells is reduced during the early phases of the disease, whereas the CD45RA-FOXP3 ${ }^{\text {low }}$ non- $\mathrm{T}_{\text {reg }}$ cell population is increased in patients with active $\mathrm{SLE}^{80}$. In addition, $\mathrm{T}$ cells from patients with SLE have low levels of phosphorylated STAT5 upon stimulation with IL-2, suggesting an inherent $\mathrm{T}_{\text {reg }}$ cell defect ${ }^{81}$. A small study reported decreased numbers of $\mathrm{T}_{\text {reg }}$ cells in the kidneys of patients with lupus nephritis and anti-neutrophil cytoplasmic antibody-associated vasculitis ${ }^{82}$; this finding suggests that $\mathrm{T}_{\text {reg }}$ cells are involved in the repair of tissue damage and that approaches to direct $\mathrm{T}_{\text {reg }}$ cells to the kidney could be therapeutically useful.

\section{Organ-specific autoimmune diseases}

In type 1 diabetes (T1D), inflammatory cells infiltrate the pancreatic islets and destroy the insulin-producing cells. The number of $\mathrm{T}_{\text {reg }}$ cells is reduced during the early phases of the disease ${ }^{83}$. This numerical deficiency is exacerbated by their reduced ability to increase the expression of FOXP3 in response to IL-2 (REF. ${ }^{84}$ ) and the resistance of $\mathrm{T}_{\text {eff }}$ cells to suppression ${ }^{85}$.

Psoriasis is an inflammatory skin disease in which the dermis and subcutaneous tissue are infiltrated with $\mathrm{T}_{\mathrm{H}} 1$ cells, $\mathrm{T}_{\mathrm{H}} 17$ cells and other subsets of $\mathrm{T}$ cells that produce pro-inflammatory cytokines including TNF, IL-6, IFN $\gamma$ and IL-17 (REF ${ }^{86}$ ). In patients with psoriasis, $\mathrm{T}_{\mathrm{reg}}$ cells, particularly those that express CCR5 (REF. ${ }^{87}$ ) and are present in the $\operatorname{skin}^{88}$ or the bone marrow ${ }^{89}$, display poor function. More importantly, the local skin inflammatory milieu promotes $\mathrm{T}_{\text {reg }}$ cell plasticity and differentiation into IL-17-producing cells ${ }^{90}$.

Myasthenia gravis is characterized by worsening muscle weakness - the pathology originates from autoreactive $\mathrm{T}$ cells, which provide help to $\mathrm{B}$ cells to produce anti-acetylcholine receptor (ACHR) antibodies, which block the ACHR. $\mathrm{T}_{\text {reg }}$ cells from patients with myasthenia gravis display decreased expression of FOXP3 and compromised suppressive function ${ }^{91,92}$, which could reflect reduced IL-2-STAT5 signalling ${ }^{93}$. Finally, the expression of CTLA4, which has been linked to myasthenia gravis in genome-wide studies ${ }^{94}$, is reduced on $\mathrm{T}_{\text {reg }}$ cells from patients with this disease ${ }^{95}$.

$\mathrm{T}_{\text {reg }}$ cells residing in the intestine of patients with inflammatory bowel disease (IBD) exhibit a normal phenotype and are functional in assays in vitro ${ }^{96}$. The number of $\mathrm{T}_{\text {reg }}$ cells in the lamina propria under any condition of intestinal inflammation is increased, whereas the number is decreased in the periphery ${ }^{97,98}$. It should be noted that $\mathrm{T}_{\text {reg }}$ cells that are present in the lamina propria of patients with IBD do not suppress $\mathrm{T}_{\text {eff }}$ cells because the TGF $\beta$ signalling pathway is defective in the intestinal 
mucosa $\mathrm{a}^{99}$. The regulation of the inflammatory response in the gut and the balance between $\mathrm{T}_{\text {reg }}$ cells, $\mathrm{T}_{\text {eff }}$ cells and innate lymphoid cells are complex ${ }^{100}$. Substantial insights have been gained from the study of the contribution of the microbiota ${ }^{101}$, as has added complexity.

Multiple sclerosis is a chronic inflammatory demyelinating disease of the central nervous system, and myelin-specific autoreactive $\mathrm{T}_{\text {eff }}$ cells initiate a chronic autoimmune response within the central nervous system $^{102}$. Experiments in a mouse model of multiple sclerosis showed that $\mathrm{T}_{\text {reg }}$ cells are generated from encephalitogenic $\mathrm{T}$ cells that infiltrate the central nervous system ${ }^{103}$, but these cells fail to control autoimmune inflammation ${ }^{104}$. In patients with multiple sclerosis, the number of $\mathrm{T}_{\text {reg }}$ cells is variable ${ }^{105}$, but these cells have compromised regulatory function ${ }^{106}$.

\section{Transplantation}

In transplanted organs, where the active alloimmune responses take place, $\mathrm{T}_{\text {reg }}$ cells that develop in response to antigen presented directly by the donor APCs or by self APCs expand and gradually infiltrate the transplanted organ. Yet, early after transplantation, $\mathrm{T}_{\text {reg }}$ cells fail to suppress the alloimmune inflammatory response ${ }^{107,108}$. Inhibition of mTOR can simultaneously suppress $\mathrm{T}_{\text {eff }}$ cell function and improve the ability of $\mathrm{T}_{\text {reg }}$ cells to control the inflammatory response. Donor alloantigen-specific $\mathrm{T}_{\text {reg }}$ cells are more effective and have substantially less nonspecific immunosuppression than polyclonal $\mathrm{T}_{\mathrm{reg}}$ cells. Polyclonal $\mathrm{T}_{\text {reg }}$ cells can suppress $\mathrm{T}_{\text {eff }}$ cells of various specificities (dominant suppression), and they can suppress $\mathrm{T}_{\text {eff }}$ cells generated in response to alloantigens other than that for which they were originally induced (bystander suppression) $^{109,110}$.

\section{Cancer}

$\mathrm{T}_{\text {reg }}$ cell numbers are increased in the circulation and within tumour sites of various tumour types in humans and mice. Mechanisms that lead to intratumoural $\mathrm{T}_{\text {reg }}$ cell accumulation include increased recruitment through the interaction of chemokine receptor-expressing activated $\mathrm{T}_{\text {reg }}$ cells and the chemokines that are produced in the tumour microenvironment ${ }^{111,112}$ (CCL2-CCR4 (REF. $\left.{ }^{113}\right)$, CCL5-CCR5, hypoxia-mediated CCL8-CCR10 (REFS $^{114,115}$ ) and CXCL12-CXCR4), local expansion of $\mathrm{tT}_{\text {reg }}$ cells ${ }^{111,112,116}$ and higher resistance of $\mathrm{T}_{\text {reg }}$ cells than $\mathrm{T}_{\text {eff }}$ cells to the reactive oxygen species in the tumour microenvironment, which results in a relative increase in $\mathrm{T}_{\text {reg }}$ cell number ${ }^{117,118}$. Another possibility is that $\mathrm{pT}_{\text {reg }}$ cells that are generated de novo from conventional $\mathrm{CD} 4^{+}$ cells in the tumour microenvironment ${ }^{119-121}$, but this has been challenged by TCR profiling studies, which did not show that the TCR repertoires in intratumoural $\mathrm{T}_{\text {reg }}$ cells and conventional CD4 $4^{+} \mathrm{T}$ cells are largely overlapping in carcinogen-induced mouse ${ }^{122}$ and human ${ }^{123}$ tumours. The second challenge to this theory is that intratumoural $\mathrm{T}_{\text {reg }}$ cells originate from $\mathrm{t} \mathrm{T}_{\text {reg }}$ cells, which recognize self-antigens specific to the organ of cancer origin $^{124,125}$. Finally, tumour-generated metabolites may favour intratumoural retention and survival of $\mathrm{T}_{\text {reg }}$ cells over $\mathrm{T}_{\text {eff }}$ cells. Specifically, the increased glycolytic activity of cancer cells may create a glucose-deprived, lactic acidenriched and fatty acid-enriched microenvironment, which favours $\mathrm{T}_{\text {reg }}$ cell survival, as these cells utilize fatty acid oxidation and oxidative phosphorylation to generate energy, whereas $\mathrm{T}_{\text {eff }}$ cells utilize aerobic glycolysis and anabolism for their bioenergetics needs ${ }^{126,127}$. High levels of IDO $^{128}$ and adenosine $e^{129}$ in the cancer microenvironment may be additional supportive mechanisms for intratumoural $\mathrm{T}_{\text {reg }}$ cell generation and function.

The intratumoural accumulation of $\mathrm{T}_{\text {reg }}$ cells has been associated with metastatic disease in several mouse tumour models ${ }^{118,130}$ and, more importantly, with advanced-stage disease and decreased survival in patients with cancer ${ }^{131}$. Furthermore, a reduced $\mathrm{CD}^{+} \mathrm{T}$ cell to $\mathrm{T}_{\text {reg }}$ cell ratio in the tumour site is predictive of poor clinical outcome ${ }^{132}$. Collective experimental and clinical evidence supports the notion that intratumoural $\mathrm{T}_{\text {reg }}$ cells facilitate tumour growth and progression by suppressing antitumour immune responses, promoting tumour angiogenesis ${ }^{114,115}$ and stimulating metastasis via receptor activator of NF- $\mathrm{\kappa B}$ ligand (RANKL; also known as TNFSF11) signalling ${ }^{133}$. Some studies indicated a better prognosis for colorectal cancers with FOXP3 ${ }^{+} \mathrm{T}$ cell infiltrates ${ }^{134}$. However, a recent study showed that certain colorectal cancers contain an abundance of FOXP $3{ }^{\text {low }} \mathrm{CD} 45 \mathrm{RA}^{-}$non- $\mathrm{T}_{\text {reg }}$ cells, which secrete pro-inflammatory cytokines, and that these patients have a better prognosis than those with a predominant FOXP $3{ }^{\text {high }}$ CD45RA ${ }^{-} \mathrm{T}_{\text {reg }}$ cell population ${ }^{135}$. This difference in FOXP3 expression could account for the conflicting data, as the distinction between FOXP $3^{\text {low }}$ cells and FOXP $3^{\text {high }}$ cells by immunohistochemistry could have been difficult. Tumour-resident $\mathrm{T}_{\text {reg }}$ cells may suppress cytotoxic immune responses by contact-dependent (involving CTLA4, programmed cell death 1 ligand 1 (PD-L1), LAG3, NRP1, CD39 or CD73) or contactindependent (involving IL-10, TGF $\beta$, granzyme, galectin 1 , adenosine, prostaglandin $\mathrm{E} 2\left(\mathrm{PGE}_{2}\right)$ or IDO) mechanisms or may acquire unique tumour-specific immunoregulatory mechanisms, as recently reported for specialized tissue-resident $\mathrm{T}_{\text {reg }}$ cells that were epigenetically reprogrammed to express tissue-appropriate molecules ${ }^{136}$. In this way, tumours may behave as newly formed tissues with specialized immunoregulatory microenvironments. For example, a recent report indicates that the SEMA4A-NRP1 pathway is utilized by $\mathrm{T}_{\text {reg }}$ cells to potentiate their function exclusively in tumours and not in other tissues ${ }^{67}$. Understanding the tumour-specific mechanisms that $\mathrm{T}_{\text {reg }}$ cells utilize for their function will help design more effective and less toxic cancer immunotherapies.

\section{Therapies: autoimmunity and transplants}

As there is a homeostatic balance between the regulatory and effector arms of the immune response, any autoimmune or inflammatory disease marks the failure of the regulatory arm to efficiently control the effector arm ${ }^{10}$ and thus implies $\mathrm{T}_{\text {reg }}$ cell insufficiency. Importantly, this does not necessarily indicate a $\mathrm{T}_{\text {reg }}$ cell numerical or functional deficiency but only defective overall performance. Current treatment of autoimmune or inflammatory diseases focuses on the reduction of the effector 
arm of the immune response with nonspecific immunosuppressant drugs. The discovery of $\mathrm{T}_{\text {reg }}$ cells and the understanding of the balance between the effector and regulatory arms of the immune response have opened the path to approaches to expand the overall capacity of $\mathrm{T}_{\text {reg }}$ cells to tilt the balance against the inflammatory process. Now, drugs and biologics are needed to improve $\mathrm{T}_{\text {reg }}$ cell performance (FIG. 2).

\section{Polyclonal $T_{\text {reg }}$ cell therapies}

In the absence of a specific means to activate and expand $\mathrm{T}_{\text {reg }}$ cells in vivo, their therapeutic potential was first explored as cell therapy (TABLE 1). This raised the important question of how to purify these cells efficiently without contamination by $\mathrm{T}_{\text {eff }}$ cells. Indeed, the best marker to characterize $\mathrm{T}_{\text {reg }}$ cells, FOXP3, is a nuclear transcription factor and as such is not suitable to purify viable cells by flow cytometry, and the CD25 membrane marker that is constitutively and highly expressed by most $\mathrm{T}_{\text {reg }}$ cells is also transiently expressed by $\mathrm{T}_{\text {eff }}$ cells. Initial clinical trials used magnetic bead sorting of $\mathrm{T}_{\text {reg }}$ cells with the expectation that this process would enrich for cells expressing high levels of CD25, including $\mathrm{T}_{\text {reg }}$ cells. The advent of clinical grade fluorescence-activated cell sorting allowed the addition of low expression of CD127 as an additional marker, which improved purification ${ }^{137}$. The first therapeutic evaluation of ex vivo-expanded polyclonal $\mathrm{T}_{\text {reg }}$ cells was performed in haematopoietic stem cell transplantation (HSCT) and T1D using polyclonal $\mathrm{T}_{\text {reg }}$ cells (FIG. 3).

Preclinical data in mice demonstrated that $\mathrm{T}_{\text {reg }}$ cells control alloimmune responses. Indeed, $\mathrm{T}_{\text {reg }}$ cell depletion exacerbated graft-versus-host disease (GVHD) after allogeneic HSCT, and $\mathrm{T}_{\text {reg }}$ cell repletion controls $\mathrm{GVHD}^{138,139}$. This preclinical information provided the needed rationale to investigate $\mathrm{T}_{\mathrm{reg}}$ cell-based therapies to control GVHD in humans. A number of small-scale efforts that gauge toxicity and clinical efficacy have been reported, including the administration of autologous peripheral blood $\mathrm{T}_{\text {reg }}$ cells expanded in vitro to patients with acute or chronic GVHD ${ }^{140,141}$ and the administration of partially human leukocyte antigen (HLA)matched $\mathrm{T}_{\text {reg }}$ cells from cord blood in conjunction with a classical GVHD prophylaxis regimen that consists of cyclosporine, sirolimus or mycophenolate mofetil ${ }^{142}$. In solid organ transplantation, the ONE study (performed by a consortium of institutions supported by the European Union) has investigated the safety and efficacy of $\mathrm{T}_{\text {reg }}$ cells administered in a dose-escalating approach (from 0.5 million to 3.0 million cells per $\mathrm{kg}$ body weight) in order to examine both safety and potential efficacy ${ }^{143}$.

It is estimated that, at the onset of T1D, approximately half of the $\beta$-cell mass remains functional and produces insulin but will be destroyed within a year. The administration of potent immunosuppressant drugs shortly after the onset of T1D can block the autoimmune process and prolong the 'honeymoon' period of the disease, but this occurs at the expense of severe side effects ${ }^{144,145}$. This information strongly supports the exploitation of immune intervention at this time of the disease by boosting the $\mathrm{T}_{\text {reg }}$ cell compartment. A first trial reported that infusion of $\mathrm{CD} 4^{+} \mathrm{CD} 25^{\text {high }} \mathrm{CD} 127^{-} \mathrm{T}_{\text {reg }}$ cells prolonged the honeymoon phase of patients with recently diagnosed $\mathrm{T} 1 \mathrm{D}^{146}$, with clinical results lasting at least 1 year ${ }^{147}$. Another study sorted $\mathrm{CD} 4^{+} \mathrm{CD} 25^{\text {high }} \mathrm{CD} 127^{-} \mathrm{T}_{\text {reg }}$ cells, labelled them with deuterated glucose and injected them into patients with recent-onset T1D. Labelled cells were detected at least 1 year later, and some of the patients maintained endogenous insulin production for 2 years after treatment ${ }^{148}$.

These trials, which used large doses of polyclonal $\mathrm{T}_{\text {reg }}$ cells in HSCT and T1D, have demonstrated that $\mathrm{T}_{\text {reg }}$ cell injections are safe; that, despite extensive proliferation during ex vivo production, some of the cells can survive for long periods of time; and that there is evidence for potential therapeutic efficacy. In parallel, further clinical evaluation of ex vivo-expanded $\mathrm{T}_{\text {reg }}$ cell therapies is warranted, which also calls for improvements in $\mathrm{T}_{\text {reg }}$ cell purification and production.

The stability of these in vitro-generated $\mathrm{T}_{\mathrm{reg}}$ cells after they are infused into the patient is of obvious importance. The possibility of devising approaches to maintain the FOXP3 locus in a demethylated state is particularly enticing ${ }^{149-151}$. In one report, hydrogen sulfide maintained the expression of the methylcytosine dioxygenases TET1 and TET2, which catalyse conversion of 5 -methylcytosine to 5-hydroxymethylcytosine in the Foxp3 gene, to establish a $\mathrm{T}_{\text {reg }}$ cell-specific hypomethylation pattern and stable FOXP3 expression ${ }^{152}$. Drugs that imitate the action of hydrogen sulfide may prove of value to stabilize $\mathrm{T}_{\text {reg }}$ cells and expand their function.

\section{$T_{\text {reg }}$ cell-enhancing drugs}

As discussed above, FOXP3 inhibits the PI3K-mTOR pathway ${ }^{153}$, and several studies in mice deficient in negative regulators of this pathway showed functional impairment of $\mathrm{T}_{\text {reg }}$ cells and systemic autoimmunity ${ }^{27,68,154}$. Human $\mathrm{T}_{\text {reg }}$ cells expand efficiently in the presence of the mTOR inhibitor rapamycin ${ }^{155}$. In SLE, activated mTOR in T cells accounts for several abnormalities, including the downregulation of the TCR companion signalling molecule $\mathrm{CD} 3 \zeta$, the expansion of $\mathrm{T}_{\mathrm{H}} 17$ cell and double-negative $\mathrm{T}$ cell (express neither CD4 nor CD8) populations, which have been shown to contribute to tissue inflammation, and the contraction of $\mathrm{T}_{\text {reg }}$ cell populations ${ }^{60,156,157}$. Administration of rapamycin has been reported to improve clinical outcomes in lupus-prone mice ${ }^{158}$ and patients with SLE ${ }^{159}$ (TABLE 2). Moreover, rapamycin can block the production of antiphospholipid antibodies in lupus-prone mice $^{160}$ and improve renal allograft survival in patients with antiphospholipid syndrome ${ }^{161}$. Rapamycin is a promising drug for the treatment of patients with systemic autoimmunity and other inflammatory conditions because it normalizes numerous $\mathrm{T}$ cell functions, including those of $\mathrm{T}_{\text {reg }}$ cells. A single-arm, open-label, phase I/II trial administered the mTOR inhibitor sirolimus ( $2 \mathrm{mg}$ per day) to patients with active SLE who were unresponsive to, or intolerant of, conventional medications for 12 months ${ }^{162}$. Clinical indices revealed a major improvement in disease, concurrent with a reduced need for steroids. Sirolimus expanded the $\mathrm{T}_{\mathrm{reg}}$ cell and $\mathrm{CD}^{+}$ 


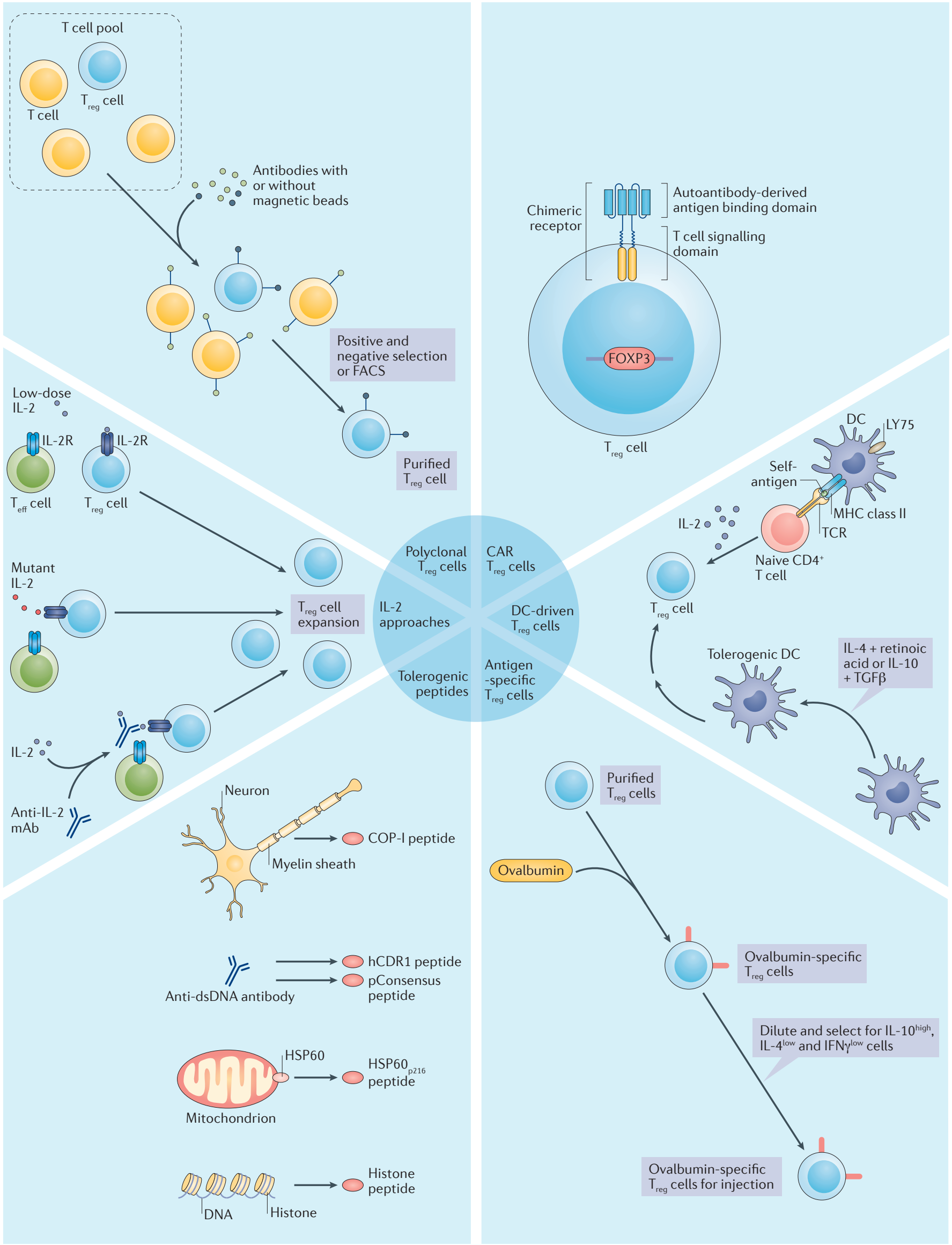


$\varangle$ Figure 2 | Therapeutic approaches to alter $\mathrm{T}_{\text {reg }}$ cells in autoimmune diseases and transplantation. The therapies are in clockwise order. Polyclonal regulatory $T\left(\mathrm{~T}_{\text {reg }}\right)$ cells can be isolated by sorting for cells with characteristic surface markers by fluorescenceactivated cell sorting or by using magnetic beads as shown. These methods have been evaluated in patients with type 1 diabetes or undergoing haematopoietic stem cell transplantation. Chimeric antigen receptor (CAR) $\mathrm{T}_{\text {reg }}$ cells are $T$ cells that have been genetically engineered to contain FOXP3 and an antigen receptor that consists of the antigen binding domain of an autoantibody and an intracellular signalling domain. Proof of concept studies have been done in xenogeneic graft-versus-host disease (GVHD), xenogeneic skin transplantation and haemophilia. Dendritic cells (DCs) that express lymphocyte antigen 75 (LY75) and present self-antigen, or that become tolerogenic because of cytokine exposure, can induce antigen-specific $T_{\text {reg }}$ cells. The latter has been tried in patients with rheumatoid arthritis, in which the tolerogenic DCs were incubated with citrullinated peptides. Peptides and copolymers with amino acid sequences that are similar to those of self-antigens can induce $T_{\text {reg }}$ cells and ameliorate disease manifestations in patients with multiple sclerosis or systemic lupus erythematosus (SLE). Finally, the highly sensitive interleukin 2 receptor (IL-2R) on $\mathrm{T}_{\text {reg }}$ cells makes low doses of IL-2 sufficient for preferential $\mathrm{T}_{\text {reg }}$ cell expansion. This approach has been tested in hepatitis $C$ virus-induced vasculitis, GVHD and SLE. The biological activity of IL-2 can be increased by forming immune complexes of IL-2 with anti-IL-2 monoclonal antibodies (mAbs), which selectively stimulate $\mathrm{T}_{\text {reg }}$ cells. COP-I, copolymer-I; dsDNA, double-stranded DNA; FACS, fluorescence-activated cell sorting; FOXP3, forkhead box P3; HSP60, heat shock protein 60; IFN $\gamma$, interferon- $\gamma$; MHC, major histocompatibility complex; TCR, T cell receptor; $T_{\text {eff }}$ cell, effector T cell; TGF $\beta$, transforming growth factor- $\beta$.

memory T cell populations and inhibited IL-4 and IL-17 production by $\mathrm{CD}^{+}$and double-negative $\mathrm{T}$ cells after 12 months $^{162}$.

Concurrent blockade of OX40L (also known as TNFSF4) and mTOR prevented graft rejection in a non-human primate GVHD model ${ }^{163}$. In a complementary approach, murine acute GVHD could be diminished with administration of FTY720, a sphingosine-1-phosphate (S1P) receptor antagonist ${ }^{164}$ that promotes the activity of $\mathrm{PP} 2 \mathrm{~A}$, thereby reducing mTOR activity $^{68}$. It is noteworthy that FTY720 is currently being studied in clinical trials to prevent acute GVHD (including EudraCT 2004-000655-41). In a different approach, patients with acute GVHD who were treated with mTOR inhibitors together with a glycolipid ( $\alpha$-galactosylceramide ( $\alpha$-GalCer) in the form of RGI-2001) that promotes NK T cell function had an increased number of $\mathrm{T}_{\text {reg }}$ cells and a reduced immune response $\mathrm{e}^{165}$.

In a negative feedback loop, FOXP3 expression is compromised when $\mathrm{mTORC} 2$ is activated, because mTORC2 prevents FOXO1 from entering the nucleus and stabilizing FOXP3 expression. Pyrazolopyrimidine derivative drugs, which promote the nuclear translocation of FOXO1 and simultaneously inhibit PI3K, are worthy of clinical investigation because they target both upstream and downstream components of mTORC2 signalling ${ }^{166}$.

Other molecules that limit mTOR activity work by diverse mechanisms of action but include S1P receptor blockers ${ }^{167,168}$, antioxidants such as metformin and $\mathrm{N}$-acetyl cysteine ${ }^{169,170}$ and calmodulin kinase type II and type IV inhibitors ${ }^{111,112}$. It remains to be seen whether any of them will generate clinical traction.

Other modalities include targeting histone acetylation with inhibitors of specific histone deacetylases (such as HDAC6, which is expressed at higher levels in $\mathrm{T}_{\text {reg }}$ cells than in conventional $\mathrm{T}$ cells). These inhibitors have been shown to selectively increase $\mathrm{T}_{\text {reg }}$ cell function in lupus-prone mice and protect them from lupus nephritis ${ }^{171,172}$. In addition, mice deficient in HDAC6 had $\mathrm{T}_{\text {reg }}$ cells with improved suppressive activity, poor antibody responses to antigen ${ }^{173}$ and curtailed autoimmune and inflammatory responses ${ }^{174}$.

\section{Antigen-specific $T_{\text {reg }}$ cell therapies}

The antigen specificity of $\mathrm{T}_{\text {reg }}$ cells is poorly understood. TCR analysis indicates that the $\mathrm{T}_{\text {reg }}$ cell repertoire is quite diverse; even the repertoire of activated $\mathrm{eT}_{\text {reg }}$ cells ${ }^{175}$, which have probably developed in response to stimulation with self-antigens ${ }^{46}$, is diverse. It is, however, not known whether protection from autoimmunity is performed by $\mathrm{T}_{\text {reg }}$ cells that recognize tissue-specific or ubiquitous self-antigens. The therapeutic efficacy of antigen-specific $\mathrm{T}_{\text {reg }}$ cells should be higher than that of polyclonal $\mathrm{T}_{\text {reg }}$ cells (reviewed previously ${ }^{176}$ ). The advent of antigen-specific $\mathrm{T}_{\text {eff }}$ cells that express a chimeric antigen receptor (CAR) and are used to treat patients with cancer ${ }^{177}$ has instigated the consideration of developing antigen-specific $\mathrm{T}_{\text {reg }}$ cell therapies (FIG. 3).

Different sources of cells and different means to generate antigen specificity can be envisioned. Indeed, it is possible to turn $\mathrm{T}_{\text {eff }}$ cells into $\mathrm{T}_{\text {reg }}$ cells by overexpressing FOXP3. Likewise, the transduction of a TCR that recognizes an autoantigen, together with FOXP3, should generate antigen-specific artificial $\mathrm{T}_{\text {reg }}$ cells. The best TCR constructs for efficient targeting and activation of $\mathrm{T}_{\text {reg }}$ cells will have to be identified, as has been done for the $\mathrm{CAR}_{\mathrm{eff}}$ cells ${ }^{116}$. Alternatively, purified antigen-specific $\mathrm{T}_{\text {reg }}$ cells could also be used.

Proof-of-concept studies in animal models of disease using CAR $\mathrm{T}_{\text {reg }}$ cells in which the CAR recognizes specific antigens have suggested the plausibility of this approach in clinical settings ${ }^{178,179}$. However, the identification of an appropriate antigen in human autoimmune diseases is challenging, particularly for conditions in which more than one antigen is involved. This issue can be somewhat easily solved in the context of transplantation or immune responses to therapeutic proteins. HLA-A2 is a frequently mismatched alloantigen in transplantation. Human HLA-A2-specific CAR $\mathrm{T}_{\text {reg }}$ cells were better than $\mathrm{T}_{\text {reg }}$ cells expressing an irrelevant CAR at preventing xenogeneic GVHD caused by HLA-A2 ${ }^{+} \mathrm{T}$ cells in mice ${ }^{179}$. Furthermore, HLA-A2 CAR $\mathrm{T}$ cells were shown to alleviate alloimmune-mediated xenogeneic skin injury ${ }^{180}$.

Investigators have also considered the construction of $\mathrm{T}_{\text {reg }}$ cells with a TCR that recognizes factor VIII in order to suppress the production of neutralizing antibodies in patients with haemophilia ${ }^{181}$; these patients often develop immune responses to injected factor VIII. These proof-of-concept studies pave the way to clinical evaluation of CAR $\mathrm{T}_{\text {reg }}$ cells in humans.

\section{IL-2}

High doses of IL-2 were initially used to promote $\mathrm{T}_{\text {eff }}$ cell function against tumours, but this approach was undermined by side effects ${ }^{182}$. The realization that $\mathrm{T}_{\text {reg }}$ cells have higher affinity receptors for IL-2 (owing to the expression of CD25) and therefore stronger IL-2R-mediated 
Table 1 | Current clinical trials studying $\mathrm{T}_{\text {reg }}$ cells in transplantation and autoimmunity

\begin{tabular}{|c|c|c|c|c|c|}
\hline $\begin{array}{l}\text { Target tissue or } \\
\text { condition }\end{array}$ & $\begin{array}{l}\mathrm{T}_{\text {reg }} \text { cell type } \\
\text { administered }\end{array}$ & Treatment groups & $\begin{array}{l}\text { Trial } \\
\text { phase }\end{array}$ & Sponsoring institute & $\begin{array}{l}\text { Clinical trial } \\
\text { identifier }\end{array}$ \\
\hline \multicolumn{6}{|l|}{ Transplantation } \\
\hline Liver & Alloantigen $\mathrm{T}_{\text {reg }}$ cells & $\begin{array}{l}\text { - i.v. } 50 \times 10^{6} \text { cells; once } \\
\text { - i.v. } 200 \times 10^{6} \text { cells; once } \\
\text { - i.v. } 800 \times 10^{6} \text { cells; once }\end{array}$ & I & NIAID & NCT02188719 \\
\hline Kidney & Alloantigen $\mathrm{T}_{\text {reg }}$ cells & $\begin{array}{l}\text { - i.v. } 300 \times 10^{6} \text { cells; once } \\
\text { - i.v. } 900 \times 10^{6} \text { cells; once }\end{array}$ & I & UCSF & NCT02244801 \\
\hline Liver & Alloantigen $\mathrm{T}_{\text {reg }}$ cells & i.v. $400 \times 10^{6}$ cells; once & $\mathrm{I} / \mathrm{II}$ & NIAID & NCT02474199 \\
\hline Liver & Autologous $\mathrm{T}_{\text {reg }}$ cells & $\begin{array}{l}\bullet \text { i.v. } 1 \times 10^{6} \text { cells per kg; once } \\
- \text { i.v. } 5 \times 10^{6} \text { cells per kg; once }\end{array}$ & $\mathrm{I} / \mathrm{II}$ & $\begin{array}{l}\text { Guy's and St Thomas' NHS } \\
\text { Foundation Trust, UK }\end{array}$ & NCT02166177 \\
\hline Islet cell & Autologous $\mathrm{T}_{\text {reg }}$ cells & $\begin{array}{l}\bullet \text { i.v. } 400 \times 10^{6} \text { cells; once } \\
- \text { i.v. } 1,600 \times 10^{6} \text { cells; once }\end{array}$ & I & $\begin{array}{l}\text { University of Alberta, } \\
\text { Canada }\end{array}$ & NCT03444064 \\
\hline $\begin{array}{l}\text { Refractory chronic } \\
\text { GVHD }\end{array}$ & Alloantigen $\mathrm{T}_{\text {reg }}$ cells & $\begin{array}{l}\text { i.v. } 0.5 \times 10^{6} \text { cells per kg; once } \\
\text { i.v. } 1.0 \times 10^{6} \text { cells per kg; once } \\
\text { i.v. } 3.0 \times 10^{6} \text { cells per kg; once }\end{array}$ & $\mathrm{I} / \mathrm{II}$ & $\begin{array}{l}\text { Instituto de Medicina } \\
\text { Molecular, Portugal }\end{array}$ & NCT02385019 \\
\hline $\begin{array}{l}\text { Refractory chronic } \\
\text { GVHD }\end{array}$ & Alloantigen $\mathrm{T}_{\text {reg }}$ cells & i.v. $1-3 \times 10^{6}$ cells; unknown regimen & II & $\begin{array}{l}\text { University Hospital } \\
\text { Regensburg, Germany }\end{array}$ & $\begin{array}{l}\text { EudraCT } \\
2012-002685-12\end{array}$ \\
\hline $\begin{array}{l}\text { Refractory chronic } \\
\text { GVHD }\end{array}$ & Alloantigen $\mathrm{T}_{\text {reg }}$ cells & i.v. $3-10 \times 10^{6}$ cells; unknown regimen & II & $\begin{array}{l}\text { University Hospital } \\
\text { Regensburg, Germany }\end{array}$ & $\begin{array}{l}\text { EudraCT } \\
\text { 2016-003947-12 }\end{array}$ \\
\hline $\begin{array}{l}\text { Refractory chronic } \\
\text { GVHD }\end{array}$ & Alloantigen $\mathrm{T}_{\text {reg }}$ cells & i.v.; unknown dose and regimen & II & CHU-ULG, Belgium & $\begin{array}{l}\text { EudraCT } \\
\text { 2012-000301-71 }\end{array}$ \\
\hline \multicolumn{6}{|c|}{ Autoimmune disorders } \\
\hline
\end{tabular}

signalling than $\mathrm{T}_{\text {eff }}$ cells suggested that administration of IL-2 at a lower dose than used for $\mathrm{T}_{\text {eff }}$ cells should promote $\mathrm{T}_{\text {reg }}$ cell expansion and function ${ }^{10}$. The demonstrated safety profile of IL-2 and its capacity to specifically activate $T_{\text {reg }}$ cells at low doses ${ }^{10}$ have delivered early clinical benefits.

Low-dose IL-2. In addition to the expression of the high-affinity receptor, $\mathrm{T}_{\text {reg }}$ cells are also intrinsically more sensitive to IL-2 than are $\mathrm{T}_{\text {eff }}$ cells ${ }^{57}$, resulting in high levels of STAT5 phosphorylation and specific enhancement of the gene activation programme downstream of IL-2R signalling ${ }^{183}$. Also, IL-2 was shown to block the differentiation of naive $\mathrm{CD} 4^{+} \mathrm{T}$ cells into pro-inflammatory $\mathrm{T}_{\mathrm{H}} 17$ cells $^{184}$ and to favourably influence the balance between $\mathrm{T}_{\mathrm{FH}}$ cells and follicular regulatory $\mathrm{T}$ cells ${ }^{185}$.

Before $\mathrm{T}_{\text {reg }}$ cells were discovered, delivery of IL-2 with a vaccinia virus containing the IL2 gene to MRL/lpr mice resulted in prolonged survival and shrinkage of the double-negative $\mathrm{T}$ cell population, particularly the population that produces IL-17 (REFS ${ }^{186,187}$ ). The dual nature of IL-2 signalling was uncovered in 1993, when mice deficient for IL-2 (REF. ${ }^{188}$ ) (and later for IL-2R signalling ${ }^{189,190}$ ) were shown to develop lethal autoimmunity and inflammation rather than immunodeficiency. $\mathrm{T}_{\text {reg }}$ cells were later found to be defective in these mice and responsible for the phenotype ${ }^{191}$. Simultaneously, investigators who had used IL-2 to treat patients with cancer noticed a major expansion of $\mathrm{T}_{\text {reg }}$ cells ${ }^{192}$. At that time, IL-2 was an approved marketed drug for activating immune effector responses to treat cancer $^{193}$, but it had numerous and severe side effects ${ }^{10}$.

The Klatzmann group initiated the first proof-ofconcept evaluation of low-dose IL-2 for the treatment of autoimmune diseases in 2006. Patients with hepatitis C virus (HCV)-induced vasculitis were known to have decreased numbers of $\mathrm{T}_{\text {reg }}$ cells, which was corrected after treatment with B cell depletors ${ }^{194}$ or antivirals ${ }^{195}$ in complete responders but not in nonresponders or partial 


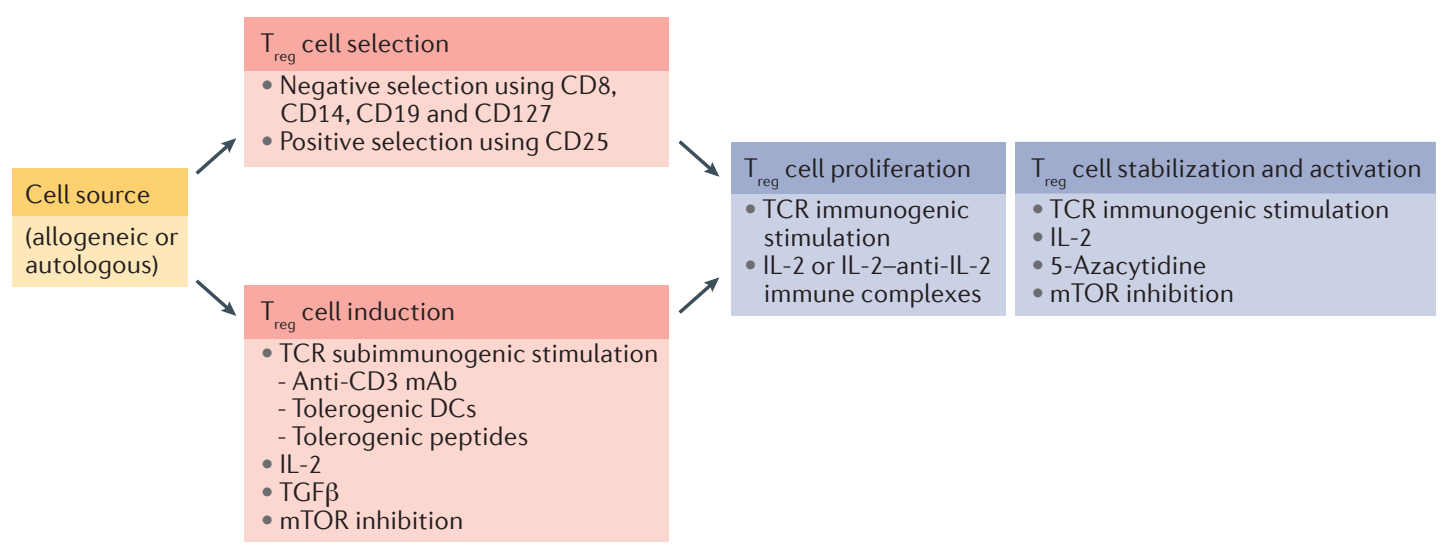

Figure $3 \mid$ The production of therapeutic $T_{\text {reg }}$ cells. There are a number of protocols for regulatory $T\left(T_{\text {reg }}\right)$ cell production in the clinical setting. The steps include choosing an appropriate cell source as well as methods for $\mathrm{T}_{\text {reg }}$ cell production (either by $T_{\text {reg }}$ cell selection or $T_{\text {reg }}$ cell induction), proliferation, stabilization and activation. $T$ cells can be sourced from the patient (autologous) or from another donor (allogeneic). $T_{\text {reg }}$ cells can be generated by one of two options. One protocol uses cell surface markers to identify the non-CD4+ T cells (CD8, CD14, CD19 and/or CD127) for negative selection, followed by positive selection of the cells with surface expression of the $\alpha$-chain of the IL-2 receptor (IL-2R) (CD25) to generate polyclonal $T_{\text {reg }}$ cells. Alternatively, to induce $T_{\text {reg }}$ cells, the T cell receptor $(T C R)$ is stimulated in the presence of IL-2 and transforming growth factor- $\beta$ (TGF $\beta$ ). The amount of TCR stimulation should be low enough to preferentially stimulate $T_{\text {reg }}$ cells. Exposure to IL-2, TGF $\beta$ and mechanistic target of rapamycin (mTOR) inhibitors, together with TCR engagement, initiates the expression of forkhead box P3 (FOXP3). To produce antigen-specific cells, the cells are stimulated with either tolerogenic dendritic cells (DCs) or tolerogenic peptides (instead of using the more common method of TCR stimulation, anti-CD3 monoclonal antibodies (mAbs)). In the next stage, the selected or induced $\mathrm{T}_{\text {reg }}$ cells are expanded using strong TCR stimulation in the presence of either IL-2 or IL-2-anti-IL-2 immune complexes. Additionally, the proliferating $\mathrm{T}_{\text {reg }}$ cells can be supplemented with 5-azacytidine and $\mathrm{mTOR}$ inhibitors to stabilize FOXP3 expression and increase $\mathrm{T}_{\text {reg }}$ cell function.

responders. This suggested that $\mathrm{T}_{\text {reg }}$ cell stimulation drives the clinical response. Daily doses of IL-2 that were about 30 -fold lower than those used in patients with cancer were administered to patients with HCV-induced vasculitis and resulted in expansion of $\mathrm{T}_{\text {reg }}$ cells, without affecting $\mathrm{T}_{\text {eff }}$ cells, and in substantial clinical improvement ${ }^{9}$. In a parallel study, administration of low-dose IL-2 to patients who had developed GVHD and were resistant to steroids resulted in a preferential expansion of $\mathrm{T}_{\text {reg }}$ cells and clinical improvement ${ }^{196}$. Indeed, very low doses of IL-2 have even been used to prevent the development of $\mathrm{GVHD}^{197}$. Low-dose IL-2 has been used in patients with alopecia areata, characterized by autoimmune-mediated hair loss, and showed impressive hair regrowth in a subset of patients ${ }^{198}$. Importantly, this study documented that the IL-2 administration expanded $\mathrm{T}_{\text {reg }}$ cell populations not only in the blood but also at the hair follicles, the site of the autoimmune process.

Several reports have demonstrated clinical improvement and expansion of the $\mathrm{T}_{\text {reg }}$ cell population in patients with SLE following administration of low-dose IL-2 $\left(\right.$ REFS $\left.^{199-201}\right)$. A caveat to this observed success is early evidence that the IL-2-IL-2R-STAT5 signalling pathway in $\mathrm{T}$ cells is compromised in many patients with $\mathrm{SLE}^{81}$, and, thus, administration of IL-2 to those patients is unlikely to improve the disease. However, because IL- 2 has the potential to reverse several pathogenic processes involved in the development of SLE, including poor $\mathrm{T}_{\text {reg }}$ cell function, increased IL-17 production, increased $\mathrm{T}_{\mathrm{FH}}$ cell activity and an expanded population of double-negative T cells ${ }^{202}$, controlled studies could reveal clinical usefulness.
As IL-2 can activate $\mathrm{T}_{\text {eff }}$ cells or $\mathrm{T}_{\text {reg }}$ cells in a dosedependent manner and its side effects are also dosedependent, defining the therapeutic window for safe and specific activation of $\mathrm{T}_{\text {reg }}$ cells is crucial. On the basis of a dose-finding double-blind placebo-controlled study ${ }^{203}$, a dose of 1-2 million international units (MIU) per injection is used in an ongoing phase IIb trial in SLE and T1D. This dose allows for a $100-200 \%$ increase in $\mathrm{T}_{\text {reg }}$ cell numbers after five injections.

Results of early clinical trials have confirmed the excellent safety profile of low-dose IL-2 and, other than local reactions at the injection sites, have shown no severe side effects. Low-dose IL-2 has been tried in a variety of autoimmune diseases and has had clinical benefit linked to increased numbers of $\mathrm{T}_{\text {reg }}$ cells (D.K., unpublished observations). Ongoing registered clinical trials addressing the clinical efficacy of low-dose IL-2 are listed in TABLE 3.

Modified IL-2. In more inflammatory settings, such as in rheumatoid arthritis or during flares of various autoimmune diseases, it may be necessary to achieve more than a $200 \%$ increase in $\mathrm{T}_{\text {reg }}$ cell numbers. Intense work has therefore been put into generating mutant IL-2 proteins that have increased specificity for $\mathrm{T}_{\text {reg }}$ cells over $\mathrm{T}_{\text {eff }}$ cells ${ }^{204}$.

Another approach to improve the potential therapeutic utility of IL-2 is to increase its half-life. The halflife of IL-2 after subcutaneous injection is a few hours, although its effect on $\mathrm{T}_{\text {reg }}$ cells is dose-dependent and lasts much longer. Current trials often use IL- 2 in a series of three to five injections repeated over weeks or single weekly injections. Pegylation ${ }^{205}$ or fusion of IL-2 with 
Table 2 | Current clinical trials with small molecules to improve $\mathrm{T}_{\text {reg }}$ cell function

\begin{tabular}{llll} 
Drug & Autoimmune disease & Trial phase & Clinical trial identifier \\
\hline Rapamycin & T1D & II & NCT02803892 and NCT02505893 \\
Metformin & SLE flares & IV & NCT02741960 \\
N-Acetyl cysteine & SLE and MS & I/II and II & NCT00775476 and NCT02804594
\end{tabular}

MS, multiple sclerosis; SLE, systemic lupus erythematosus; T1D, type 1 diabetes; $T_{\text {reg }}$ cell, regulatory $T$ cell.

carrier proteins such as immunoglobulin fragments ${ }^{206}$ or albumin ${ }^{207,208}$ increases its half-life (FIG. 3). However, these approaches risk rendering the recombinant fusion proteins immunogenic or even able to stimulate $\mathrm{T}_{\text {eff }}$ cells. The trade-off between ease of use and risks now needs to be investigated.

Complexing IL-2 with antibodies that affect its binding to the trimeric or dimeric IL-2Rs has also been explored $^{209}$. Some of these complexes preferentially expand $\mathrm{T}_{\text {reg }}$ cell populations and improve disease in lupus-prone mice ${ }^{187}$. Although the initial development used murine antibodies, the identification of human antibodies or the humanization of murine antibodies that can confer increased specificity of IL-2 complexes for $\mathrm{T}_{\text {reg }}$ cells would allow their use in the clinic. Human antibodies that favour the expansion of $\mathrm{T}_{\text {eff }}$ cells over $\mathrm{T}_{\text {reg }}$ cells have been described ${ }^{210}$, and recently, a fully human anti-IL-2 antibody, which stabilizes IL-2 in a conformation that results in the preferential STAT5 phosphorylation of $\mathrm{T}_{\text {reg }}$ cells in vitro and selective expansion of $\mathrm{T}_{\text {reg }}$ cells in vivo, has been developed ${ }^{211}$.

\section{Dendritic cells}

Lymphocyte antigen 75 (LY75; also known as DEC-205 and CD205) belongs to the lectin family of surface receptors that function as antigen uptake and processing receptors for tolerogenic $\mathrm{DCs}^{212}$. Thus, cognate antigen presentation by immature $\mathrm{LY}^{+} 5^{+} \mathrm{DCs}$ to naive $\mathrm{CD} 4^{+} \mathrm{T}$ cells can promote the development of functional $\mathrm{T}_{\text {reg }}$ cells that have the canonical $\mathrm{T}_{\text {reg }}$ cell signature (including expression of chemokine receptors, CTLA4 and IL-10 $)^{44}$. In these $\mathrm{T}_{\text {reg }}$ cells, the CNS2 region of the FOXP3 promoter is hypomethylated and allows for stable expression of FOXP3 and prolonged cell survival ${ }^{213}$. In the preclinical setting, $\mathrm{LY}^{+} 5^{+} \mathrm{DCs}$ promoted tolerance through the generation of $\mathrm{T}_{\text {reg }}$ cells and protected mice from the development of T1D and experimental autoimmune encephalomyelitis (EAE), which result from pancreas-embedded ${ }^{214}$ and myelin oligodendrocyte glycoprotein (MOG) ${ }^{215}$ antigens, respectively.

Tolerogenic DCs can be generated by exposing DCs to either IL-4 and retinoic acid or IL-10 and TGF $\beta$. DCs from patients with rheumatoid arthritis cultured under such conditions led to the development of $\mathrm{T}_{\text {reg }}$ cells and $\mathrm{T}_{\mathrm{H}} 2$ cells in culture, both of which produced immunosuppressive cytokines ${ }^{216}$. This approach has been tried in patients with rheumatoid arthritis in a phase I clinical trial wherein the patients were treated with autologous tolerogenic DCs that were differentiated ex vivo from peripheral blood mononuclear cells in the presence of IL-4, granulocyte-macrophage colony-stimulating factor (GM-CSF) and an NF- $\kappa B$ inhibitor and treated with citrullinated peptides (Rheumavax). These tolerogenic DCs were then injected intradermally to 18 patients with rheumatoid arthritis who carried the shared HLA-DR epitope, which recognizes the citrullinated peptides. The treatment was safe and biologically active, and 1 month after the injection, the number of $\mathrm{T}_{\text {eff }}$ cells decreased, the ratio of $\mathrm{T}_{\text {reg }}$ cells to $\mathrm{T}_{\text {eff }}$ cells increased, and serum levels of inflammatory cytokines and chemokines (IL-15, IL-29, CXCL1 and CXCL11) were reduced ${ }^{217}$.

\section{Tolerogenic peptides}

Myelin basic protein (MBP) is an antigen derived from myelin sheaths. A polypeptide known as copolymer-I (COP-I), which contains the four immunogenic amino acids found in MBP, was designed and proved clinically efficient in treating patients with multiple sclerosis ${ }^{218}$. In the murine model of EAE, administration of COP-I was associated with induction of $\mathrm{T}_{\text {reg }}$ cells ${ }^{219}$.

A human anti-double-stranded DNA monoclonal antibody was the basis for the design of the hCDR1 peptide, which, when administered to mice and humans with lupus, resulted in clinical improvement and induction of FOXP3-expressing $\mathrm{T}$ cells $\mathrm{s}^{220,221}$ that also expressed BCL- $\mathrm{X}_{\mathrm{L}}\left(\mathrm{REFS}^{222,223}\right)$. In a phase II clinical trial wherein patients with SLE were treated with four different doses of hCDR1, the peptide was safe and well tolerated with some promise of clinical benefit ${ }^{224}$.

Both histone peptides derived from a histone autoepitope and the pConsensus peptide, which is based on $\mathrm{T}$ cell determinants in the variable chain heavy $\left(\mathrm{V}_{\mathrm{H}}\right)$ region of a murine anti-DNA antibody, were beneficial in treating lupus-prone mice, and both approaches involved the induction of both $\mathrm{CD}^{+}$and $\mathrm{CD}^{+} \mathrm{T}_{\text {reg }}$ cells ${ }^{225,226}$.

A peptide derived from heat shock protein 60 (HSP60), designated HSP60 ${ }_{\mathrm{p} 216}$, was shown to be tolerogenic in a murine model for rheumatoid arthritis. HSP $60_{\mathrm{p} 216}$-specific CD8 ${ }^{+} \mathrm{T}_{\text {reg }}$ cells were induced following the administration of tetramers composed of HSP60 ${ }_{\mathrm{p} 216}$ and the murine MHC class Ib molecule Qa1. These cells used perforin and IL-15 to suppress pathogenic $\mathrm{T}_{\mathrm{FH}}$ cells and $\mathrm{T}_{\mathrm{H}} 17$ cells, reduce the production of collagen-specific autoantibodies and inhibit the development of arthritis in these mice ${ }^{227}$.

A different approach to developing tolerogenic peptides for rheumatoid arthritis utilizes the citrullination of peptides, as anti-citrullinated peptide antibodies are a hallmark of this disease. Thus, a multi-epitope peptide was designed that contained sequences of citrullinated human autoantigens (such as type II collagen, vimentin, fibrinogen and filaggrin). This compound (Cit-ME) induced $\mathrm{T}_{\text {reg }}$ cells and improved clinical indices in a rat adjuvant-induced arthritis model ${ }^{228}$. 
Table 3 | Current clinical trials studying low-dose IL-2

\begin{tabular}{|c|c|c|c|c|}
\hline Target tissue or condition & Treatment groups & $\begin{array}{l}\text { Trial } \\
\text { phase }\end{array}$ & Sponsoring institute & $\begin{array}{l}\text { Clinical trial } \\
\text { identifier }\end{array}$ \\
\hline \multicolumn{5}{|l|}{ Transplantation } \\
\hline \multirow[t]{2}{*}{ Liver } & s.c. $0.30 \mathrm{MIU}$ per $\mathrm{m}^{2}$ body surface area for 4 weeks & II & BIDMC, Boston, USA & NCT02739412 \\
\hline & Unknown dose; 4 weeks & IV & King's College London, UK & NCT02949492 \\
\hline \multicolumn{5}{|l|}{ Autoimmune diseases } \\
\hline $\begin{array}{l}\text { Rheumatoid arthritis, ankylosing } \\
\text { spondylitis, SLE, psoriasis, IBD } \\
\text { and autoimmune hepatitis }\end{array}$ & $\begin{array}{l}\text { - Induction: s.c. } 1 \text { MIU per day for } 5 \text { days } \\
\text { - Maintenance: s.c. } 1 \text { MIU every } 15 \text { days for } 6 \text { months } \\
\text { - Maintenance (in SLE): s.c. } 1 \text { MIU every } 7 \text { days for } \\
6 \text { months }\end{array}$ & ॥ & $\begin{array}{l}\text { Assistance Publique- } \\
\text { Hôpitaux de Paris, France }\end{array}$ & NCT01988506 \\
\hline SLE & s.c. 1.5 MIU per day for 5 days every 3 weeks; 4 cycles & ॥ & $\begin{array}{l}\text { University of Zurich, } \\
\text { Switzerland }\end{array}$ & NCT03312335 \\
\hline Multiple sclerosis & $\begin{array}{l}\text { - Induction period: repeated administration of } \\
\text { low-dose IL-2 } \\
\text { - Maintenance period: treatment with IL-2 }\end{array}$ & II & $\begin{array}{l}\text { Assistance Publique- } \\
\text { Hôpitaux de Paris, France }\end{array}$ & NCT02424396 \\
\hline
\end{tabular}

BIDMC, Beth Israel Deaconess Medical Center; CHU, Centre Hospitalier Universitaire; IBD, inflammatory bowel disease; IL, interleukin; MIU, million international

A general limitation of using tolerogenic peptides is the fact that the autoimmune response spreads to different epitopes, even those located on the same protein ${ }^{229}$, and, thus, the peptide may lose efficacy over time.

\section{Limitations and considerations}

Although therapies that promote $\mathrm{T}_{\text {reg }}$ cells have great potential, there are some caveats to their prospective use. Information generated in mice may not be readily transferable to humans because human and murine $\mathrm{T}_{\text {reg }}$ cells are not identical. For instance, some human $\mathrm{T}_{\text {reg }}$ cell subsets are not suppressive, whereas murine $\mathrm{T}_{\text {reg }}$ cells are functionally more homogeneous. Patients with established autoimmune disease already harbour high numbers of autoreactive $\mathrm{T}_{\text {eff }}$ cells and memory $\mathrm{T}$ cells and have an inflammatory milieu that can be difficult for $\mathrm{T}_{\text {reg }}$ cells to overcome. For instance, in patients with rheumatoid arthritis, the inflammatory cytokines (such as IL-6 and TNF) that are present in their synovial fluid make the $\mathrm{T}_{\text {eff }}$ cells resistant to suppression by $\mathrm{T}_{\text {reg }}$ cells ${ }^{230}$. Also, the $\mathrm{T}_{\text {eff }}$ cells from patients with SLE are more resistant to suppression by $\mathrm{T}_{\text {reg }}$ cells in vitro ${ }^{79,231}$. Under such conditions, it would take a high number of autoantigen-specific $\mathrm{T}_{\text {reg }}$ cells to suppress those pathogenic cells. Projecting from data from the mouse models, it would be wise first to get rid of the autoreactive $\mathrm{T}_{\text {eff }}$ cells and only then administer $\mathrm{T}_{\text {reg }}$ cells. Approaches to increase the sensitivity of $\mathrm{T}_{\text {eff }}$ cells to the suppressive effects of $\mathrm{T}_{\text {reg }}$ cells are also needed.

For cell therapies, $\mathrm{T}_{\text {reg }}$ cells that are expanded ex vivo are not necessarily stable nor long-lived. Epigenetic changes to the expanded $\mathrm{T}_{\text {reg }}$ cells could make them stable. In the setting of ex vivo $\mathrm{T}_{\text {reg }}$ cell expansion and transfusion, it is still difficult to demonstrate $\mathrm{T}_{\text {reg }}$ cell purity and potency. It is unlikely that all of the expanded cells will be $\mathrm{T}_{\text {reg }}$ cells or that their suppressive function in vitro will necessarily be reproduced in vivo. As with any cell-based immunotherapy, treatment with $\mathrm{T}_{\text {reg }}$ cells could induce an inflammatory reaction following the cell infusion (cytokine release syndrome).

For treatment with IL-2, determining the exact IL-2 'low dose' for human studies may prove difficult because the therapeutic window may vary according to the inflammatory context, and, in some patients, it may stimulate the $\mathrm{T}_{\text {eff }}$ cells.

\section{Therapies: cancer}

As discussed above, $\mathrm{T}_{\text {reg }}$ cells enter tumours, and except for in cancers that are driven by inflammation, $\mathrm{T}_{\text {reg }}$ cells promote tumour growth and progression through multiple inhibitory pathways. Therefore, several approaches have been considered to deplete $T_{\text {reg }}$ cells, limit their entry into the tumour tissue and/or disrupt their function (TABLE 4).

\section{Nonspecific $T_{\text {reg }}$ cell targeting}

Traditional chemotherapeutics, such as cyclophosphamide and others, have been shown to reduce the number and immunosuppressive function of $\mathrm{T}_{\text {reg }}$ cells through various mechanisms ${ }^{115}$. Low-dose cyclophosphamide (known as metronomic chemotherapy) was reported to deplete $\mathrm{T}_{\text {reg }}$ cells by inhibiting proliferation and inducing apoptosis and to decrease their function by reducing FOXP3 and GITR expression ${ }^{232,233,234}$. In addition, tyrosine kinase inhibitors (sunitinib, sorafenib and imatinib) have been shown to inhibit intratumoural $\mathrm{T}_{\text {reg }}$ cell expansion and function ${ }^{117,235,236}$. However, although these approaches can limit $\mathrm{T}_{\text {reg }}$ cell proliferation and function, they are not an ideal choice, as they are not specific to tumour-associated $\mathrm{T}_{\text {reg }}$ cells.

\section{Blocking $T_{\text {reg }}$ cell trafficking into tumours}

Tumours have microenvironments rich in cytokines and chemokines that promote the accumulation of $\mathrm{T}_{\text {reg }}$ cells, which express high levels of chemokine receptors ${ }^{237,238}$. 
Blocking the interactions between chemokines and their receptors - such as that of CCL22 and CCR4, which constitutes the dominant intratumoural $\mathrm{T}_{\text {reg }}$ cell recruitment mechanism in numerous tumours - reduces intratumoural accumulation of $\mathrm{T}_{\text {reg }}$ cells and suppresses tumour growth in mice ${ }^{238,239}$. Similarly, intraperitoneal injection of an anti-CCR10 immunotoxin in mice with orthotopically implanted human ovarian carcinoma cells that showed hypoxia-induced overexpression of CCL28 (the ligand for CCR10) resulted in complete intratumoural $\mathrm{T}_{\text {reg }}$ cell depletion and reduced tumour growth ${ }^{114}$. Clinical studies conducted with a humanized anti-CCR4 antibody (mogamulizumab, KW-0761), which depletes CCR4 ${ }^{+}$ $\mathrm{T}_{\text {reg }}$ cells by antibody-dependent cell-mediated cytotoxicity (ADCC), showed intratumoural $\mathrm{T}_{\text {reg }}$ cell depletion and antitumour activity with minimal to moderate toxicity ${ }^{240,47}$. However, a recent update of two clinical phase I/II trials reported unclear long-term antitumour effects ${ }^{241}$. Occasional serious side effects were reported as well ${ }^{240,242}$. Comparative flow cytometric and RNA sequencing analysis of $\mathrm{T}_{\text {reg }}$ cells and conventional $\mathrm{T}$ cells in tumour and normal tissues and in the circulation of patients with breast carcinoma showed that CCR4, in addition to being highly expressed in intratumoural $\mathrm{T}_{\text {reg }}$ cells, is also expressed in $\mathrm{T}_{\text {reg }}$ cells in the peripheral blood and in activated $\mathrm{T}_{\text {eff }}$ cells, although in somewhat lesser amounts ${ }^{123}$. It is therefore possible that the CCR4-depleting antibody affects the survival of peripheral $\mathrm{T}_{\text {reg }}$ cells, which leads to unwanted effects, and affects the survival of $\mathrm{T}_{\text {eff }}$ cells as well, which limits antitumour responses. Indeed, both $\mathrm{T}_{\text {reg }}$ cell and $\mathrm{T}_{\text {eff }}$ cell numbers were decreased in patients who received anti-CCR4 antibody treatment in a clinical study $^{243}$. These data highlight the need to identify molecules that are specific to tumour-dwelling $\mathrm{T}_{\text {reg }}$ cells to use as therapeutic targets. Notably, two recent studies showed that intratumoural $\mathrm{T}_{\text {reg }}$ cells from various human tumours express CCR8 at levels that are much higher than those in peripheral $\mathrm{T}_{\text {reg }}$ cells, or conventional $\mathrm{T}$ cells in the periphery of tumours, indicating that CCR8 is a novel promisingly targetable molecule ${ }^{123,244}$. CCR8 is the receptor for the CCL1 and CCL18 chemokines, both of which are differentially upregulated in intratumoural myeloid cells ${ }^{123}$.

\section{$T_{\text {reg }}$ cell depletion}

Numerous specific intratumoural $\mathrm{T}_{\text {reg }}$ cell depletion strategies have been investigated and reviewed extensively ${ }^{115,117,130}$. Antibodies directed against CD25 (daclizumab, basiliximab and LMB-2 (REFS ${ }^{245-249}$ ), a single-chain variable fragment $(\mathrm{scFv})$ fused to exotoxin $\mathrm{A}$ of Pseudomonas spp.), have been used to kill $\mathrm{T}_{\text {reg }}$ cells by ADCC and complement-mediated cytotoxicity. Also, a fusion protein containing IL-2 and diphtheria toxin protein (denileukin diftitox, Ontak) was designed to induce direct cytotoxicity. Preclinical and clinical studies using a combination of anti-CD25 antibodies and DC vaccines reported beneficial effects, but clinical studies with denileukin diftitox had mixed results ${ }^{115,117,130,250}$. Notably, patients with metastatic melanoma treated with denileukin diftitox showed no clinical benefit and severe autoimmune side effects ${ }^{251}$. Depletion of $\mathrm{T}_{\text {reg }}$ cells from HSCT to treat relapses of leukaemia in patients who did not develop GVHD during the first transplant produced better outcomes ${ }^{252}$. These data suggest that global $\mathrm{T}_{\text {reg }}$ cell depletion has variable efficacy and the potential to induce systemic complications.

\section{Immune checkpoint inhibitors}

Immune checkpoint molecules are upregulated in $\mathrm{T}_{\text {reg }}$ cells and thus could be targeted to modulate $\mathrm{T}_{\text {reg }}$ cell function. A widely used approach to activate antitumour immunity is immune checkpoint blockade with antibodies against CTLA4 (ipilimumab and tremelimumab), which induce tumour regression and improve survival of patients with metastatic melanoma ${ }^{253-255}$. Although CTLA4 targeting was initially aimed to reactivate $\mathrm{T}_{\text {eff }}$ cells, CTLA4 is also highly expressed on $\mathrm{T}_{\text {reg }}$ cells, and CTLA4 targeting induces $\mathrm{T}_{\text {reg }}$ cell depletion in the tumour microenvironment by $\mathrm{ADCC}^{256}$. Furthermore, CTLA4 antibody binding to $\mathrm{T}_{\text {reg }}$ cells contributed, independently of its $\mathrm{T}_{\text {eff }}$ cell binding, to the antitumour activity of this molecule, thus leading to a synergistic maximal antitumour effect in a mouse melanoma model ${ }^{257}$. Intriguingly, however, conditional CTLA4 depletion in $\mathrm{T}_{\text {reg }}$ cells increased the immunosuppressive functions of $\mathrm{T}_{\text {reg }}$ cells in adult mice ${ }^{258}$, indicating that the role of CTLA 4 in $\mathrm{T}_{\text {reg }}$ cells needs to be further investigated. Undesirable autoimmune manifestations in a subset of patients treated with anti-CTLA4 antibodies indicated systemic loss of $\mathrm{T}_{\mathrm{reg}}$ cell activity ${ }^{253,259}$. Anti-CTLA4 antibodies have complimentary activity with therapies targeting anti-PD-1 (nivolumab), another checkpoint inhibitor expressed by $\mathrm{T}_{\text {reg }}$ cells, and their combined use is more beneficial than either agent alone ${ }^{260}$. Furthermore, because anti-CTLA4 and anti-PD-1 therapies benefit only a small subset of patients with cancer and may have undesirable effects, such as the development of autoimmune manifestations, other molecules that are expressed by $\mathrm{T}_{\text {reg }}$ cells with superior immunosuppressive activity, such as $\mathrm{T}$ cell immunoreceptor with immunoglobulin and ITIM domains (TIGIT), LAG3 and T cell immunoglobulin mucin domain 3 (TIM3; also known as HAVCR2), are being considered and evaluated in early-phase clinical trials ${ }^{261,262}$. TIM3 targeting may be more advantageous than CTLA4 and PD-1 targeting, because expression of TIM3 is restricted to intratumoural T cells, and hence its inhibition is less likely to interfere with $\mathrm{T}$ cell functions in other sites; TIM3-deficient mice do not exhibit autoimmune disorders ${ }^{263}$.

\section{Engagement of TNFRs}

GITR belongs to the group of TNFRs that provides co-stimulatory signalling to increase $\mathrm{T}$ cell activation and is induced in T cells upon activation, but GITR is also highly expressed (higher than in the periphery) in intratumoural $\mathrm{T}_{\text {reg }}$ cells. Ligation of GITR with an agonistic antibody was shown to suppress $\mathrm{T}_{\text {reg }}$ cell activity, reduce $\mathrm{T}_{\text {reg }}$ cell numbers and decrease $\mathrm{T}_{\text {reg }}$ cell lineage stability selectively in tumours and also limit tumour growth in mice ${ }^{264-267}$, particularly when administered together with CTLA4 (REF. ${ }^{268}$ ) or PD-1 inhibitors ${ }^{269}$. GITR ligation, similar to CTLA4 blockade, also improves $\mathrm{T}_{\text {eff }}$ cell functions and renders $\mathrm{T}_{\text {eff }}$ cells resistant to inhibition by $\mathrm{T}_{\text {reg }}$ cells ${ }^{270}$. Mice treated with an 
Table 4 | Current clinical approaches to suppress $T_{\text {reg }}$ cell activity in cancer

\begin{tabular}{|c|c|c|c|}
\hline Treatment & $\begin{array}{l}\text { Molecular target or } \\
\text { mechanism }\end{array}$ & Tumour type & Refs \\
\hline \multicolumn{4}{|l|}{ Nonspecific $T_{\text {reg }}$ cell depletion } \\
\hline $\begin{array}{l}\text { Cyclophosphamide, low dose } \\
\text { (metronomic chemotherapy) }\end{array}$ & DNA crosslinker & End-stage cancers and breast cancer & 232,233,234 \\
\hline Sunitinib or sorafenib & Tyrosine kinase inhibitor & Renal cell carcinoma & 235,236 \\
\hline \multicolumn{4}{|l|}{ Specific $T_{\text {req }}$ cell depletion } \\
\hline Daclizumab & Anti-CD25 mAb & Breast cancer & 246 \\
\hline LMB-2 & Anti-CD25 (scFv)-exotoxin A & Haematological malignancies and melanoma & $247-249$ \\
\hline Denileukin diftitox & IL-2-diphtheria toxin & Renal cell carcinoma & 250 \\
\hline \multicolumn{4}{|c|}{ Inhibition of $T_{\text {reg }}$ cell trafficking } \\
\hline Mogamulizumab (KW-0761) & Anti-CCR4 mAb & $\begin{array}{l}\text { CCR4-negative solid tumours, T cell } \\
\text { lymphoma or leukaemia }\end{array}$ & $\begin{array}{r}47,239, \\
240,243\end{array}$ \\
\hline \multicolumn{4}{|l|}{ Immune checkpoint inhibitors } \\
\hline Ipilimumab & Anti-CTLA4 mAb & Metastatic melanoma & $253-255,260$ \\
\hline Nivolumab & Anti-PD-1 mAb & Metastatic melanoma & 260 \\
\hline \multicolumn{4}{|l|}{ TNFR engagement } \\
\hline $\begin{array}{l}\text { BMS-986156, GWN323 and } \\
\text { INCAGN01876 }\end{array}$ & GITR agonist antibody & Advanced solid tumours & 276,278 \\
\hline MEDI11873 & $\begin{array}{l}\text { Hexameric GITR-targeted } \\
\text { human IgG1 }\end{array}$ & Advanced solid tumours & 276,278 \\
\hline 9B12 mouse anti-human mAb & OX40 agonist & Advanced solid tumours & $275,276,277$ \\
\hline \multicolumn{4}{|l|}{ IDO inhibitors } \\
\hline Indoximod & IDO & Pancreatic, prostate, brain and breast cancers & 287 \\
\hline Epacadostat & IDO & Melanoma and myelodysplastic syndrome & 287 \\
\hline Navoximod & IDO & Solid tumours & 287 \\
\hline IDO1-derived peptide & IDO & Melanoma & 287 \\
\hline
\end{tabular}

anti-GITR antibody showed dramatically reduced tumour growth and the intratumoural $\mathrm{T}_{\text {reg }}$ cells in these mice had decreased expression of HELIOS (also known as IKZF2, a transcription factor that maintains $\mathrm{T}_{\text {reg }}$ cell stability and function) and increased IFN $\gamma$ production. These data provide a mechanistic explanation for the reduction of $\mathrm{T}_{\text {reg }}$ cell lineage stability by GITR ligation and reinforce GITR as a therapeutic target to reverse the immunosuppressive function of intratumoural $\mathrm{T}_{\mathrm{reg}}$ cells. Although side effects have been reported with GITR ligation ${ }^{271}$, these may be avoided by using low doses of anti-GITR antibody, which are sufficient for $\mathrm{T}_{\text {reg }}$ cell conversion in mice ${ }^{272}$. In addition, the anti-GITR antibody has been reported to increase the number of $\mathrm{T}_{\text {reg }}$ cells in the periphery ${ }^{273,274}$.

Another TNF receptor family member, OX40, has similar pattern of expression and functional properties to GITR and, upon ligation, leads to impaired $\mathrm{T}_{\text {reg }}$ cell function and improved $\mathrm{T}_{\text {eff }}$ cell responses ${ }^{275}$. On the basis of the promising results from the animal studies, human GITR and OX40 agonists, as well as agonists for other members of the TNFR family (CD27 and 4-1BB) are currently being evaluated in clinical trials as monotherapies or in combination with other agents ${ }^{266,276-278}$.

Two newly developed antagonistic antibodies that target TNFR2, which is expressed by the most suppressive intratumoural $\mathrm{T}_{\mathrm{reg}}$ cells and by human cancers, disabled the ability of TNFR2 to bind TNF and activate NF- $\kappa B$, killed $\mathrm{T}_{\text {reg }}$ cells and also induced killing of tumour cells ${ }^{279}$. Interestingly, TNFR2 can exert bidirectional control on $\mathrm{T}_{\text {reg }}$ cells because it can induce their proliferation and activation through the NF- $\kappa \mathrm{B}, \mathrm{AP} 1$ and MAPK pathways $^{280}$. TNFR2 agonists have been used as a novel strategy to induce $\mathrm{T}_{\text {reg }}$ cell expansion in vitro and to inhibit GVHD in vivo ${ }^{281-283}$. Therefore, TNFR2 is an exciting molecular target for the development of $\mathrm{T}_{\text {reg }}$ cell-based immunomodulatory therapies to treat both cancer and autoimmune diseases using antagonistic or agonistic antibodies respectively.

\section{IDO inhibitors}

IDO, an enzyme with two isoforms (IDO1 and IDO2), converts tryptophan to kynurenine, resulting in depletion of tryptophan, a molecule that is central to T cell proliferation and differentiation. Lack of tryptophan and upregulation of kynurenine diminishes $\mathrm{T}$ cell proliferation and survival and induces the differentiation of $\mathrm{T}$ cells into $\mathrm{T}_{\text {reg }}$ cells ${ }^{128,284,285}$. In the tumour microenvironment, IDO is produced by plasmacytoid DCs and by tumour cells in response to inflammatory stimuli, such as IFN $\gamma$, which leads to decreased $\mathrm{T}_{\text {eff }}$ cell responses and increased $\mathrm{T}_{\text {reg }}$ cell responses. IDO1 is more widely expressed than IDO2 and is overexpressed and activated in many human cancers, 
often (but not always) conferring a poor prognosis ${ }^{286,287}$. IDO inhibitors (indoximod (NLG-8189), navoximod (NLG-919), epacadostat (INCB024360), BMS-986205 and others) are currently being evaluated in various clinical trials, mostly in combination with standard chemotherapy or with other immunotherapies, such as checkpoint inhibitors or tumour vaccines. The preclinical and clinical development of IDO inhibitors have been reviewed ${ }^{286}$. Preliminary studies have shown that the combination of IDO and PD-1 inhibitors is fairly safe although not entirely without side effects. Interestingly, it was reported that combined treatment of mice with melanoma with an IDO inhibitor and a tumour vaccine induced conversion of $\mathrm{T}_{\text {reg }}$ cells into $\mathrm{T}_{\mathrm{H}}$ 17-like cells in the tumour-draining lymph node and increased $\mathrm{T}_{\text {eff }}$ cell activation and antitumour efficacy, suggesting that the combined use of IDO inhibitors and tumour vaccines could be an alternative strategy to deactivate $\mathrm{T}_{\text {reg }}$ cells by converting them to $\mathrm{T}_{\text {eff }}$-like cells ${ }^{288}$.

\section{$T_{\text {reg }}$ cell-derived cytokines}

In another approach, the effects of the anti-inflammatory cytokines (TGF $\beta$, IL-10 and IL-35) that are secreted at high levels by $\mathrm{T}_{\text {reg }}$ cells in the tumour microenvironment were blocked using neutralizing antibodies. Blockade of TGF $\beta$ expressed on the surface of $\mathrm{T}_{\text {reg }}$ cells improved the anti-melanoma immune response ${ }^{282}$ and suppressed metastasis of pancreatic tumours in mice ${ }^{113,289-291}$. Anti-IL-35 limited tumour growth in multiple mouse models of human cancer $^{284}$.

\section{Novel intratumoural $T_{\text {reg }}$ cell targets}

NRP1, a receptor for the immune cell-expressed ligand SEMA4A, is selectively and highly expressed in intratumoural $\mathrm{T}_{\text {reg }}$ cells and correlates with poor prognosis in patients with melanoma ${ }^{292}$. NRP1 regulates $\mathrm{T}_{\text {reg }}$ cell function and survival in the inflammatory tumour environment through ligation with SEMA4A, and targeting this axis can inhibit intratumoural $\mathrm{T}_{\text {reg }}$ cell function ${ }^{67,293}$. NRP1-deficient intratumoural $\mathrm{T}_{\text {reg }}$ cells lose their immunosuppressive function and produce IFN $\gamma\left(\mathrm{a} \mathrm{T}_{\text {eff }}\right.$ cell cytokine) while retaining FOXP3 expression, thus exhibiting a phenotype that was named $\mathrm{T}_{\text {reg }}$ cell fragility (REF. ${ }^{293}$ ). Mice lacking NRP1 in $\mathrm{T}_{\text {reg }}$ cells or treated with blocking antibodies to NRP1 or SEMA4A exhibit delayed tumour growth and have no autoimmune responses. Furthermore, IFN $\gamma$ produced by NRP1-deficient intratumoural $\mathrm{T}_{\text {reg }}$ cells drives the fragility of adjacent NRP1-expressing $\mathrm{T}_{\text {reg }}$ cells, thereby amplifying the effect and leading to tumour regression; IFN $\gamma$ receptor inactivation abrogates the anti-PD-1 tumour response, as shown in a fibrosarcoma mouse model ${ }^{293}$. These findings indicate that NRP1 is a potential therapeutic target, which could reverse the immunosuppressive function of intratumoural $\mathrm{T}_{\text {reg }}$ cells and improve the efficacy of checkpoint blockade therapies while maintaining peripheral tolerance.

Another recent study found that the c-REL subunit of the canonical NF- $\kappa$ B pathway is required for the maintenance of the active status of $\mathrm{T}_{\text {reg }}$ cells $^{294}$. REL genetic ablation or degradation by pentoxifylline, a US Food and Drug Administration-approved drug, downregulates HELIOS and impairs the molecular identity and suppressive function of $\mathrm{T}_{\text {reg }}$ cells, indicating that c-REL can be targeted to inhibit $\mathrm{T}_{\text {reg }}$ cell function ${ }^{294}$. Pentoxifylline did not reduce growth of established tumours as a monotherapy but potentiated the effect of PD-1 blockade and was well tolerated in mice and patients.

Oxygen-sensing propyl hydroxylases promote tumour growth by inducing $\mathrm{T}_{\text {reg }}$ cell function and limiting $\mathrm{T}_{\text {eff }}$ cell function. Genetic or pharmacological inhibition of the oxygen-sensing propyl hydroxylases limits tumour metastasis to the lungs ${ }^{295}$.

Because $\mathrm{T}_{\text {reg }}$ cells in tumour tissues diversify to adapt to the tumour microenvironment, characterization of the immune features of the tumour-infiltrating cells has gained wide attention for both predicting clinical outcomes and deciding which immunotherapy may work the best ${ }^{296,297}$. The immune landscape of each tumour should probably dictate the immune approach most expected to be of clinical value.

\section{Conclusions and future directions}

Immunotherapy has been well established in the treatment of autoimmune diseases and is expected to substantially advance the treatment of cancer. In autoimmune diseases, most of the established approaches address the over-reactive autoinflammatory response and have been successful in organ-specific diseases including rheumatoid arthritis, IBD, psoriasis and others. However, parallel approaches have been discouraging for systemic autoimmune diseases. Similarly, checkpoint inhibitors have made substantial contributions in the treatment of at least certain types of tumour.

Restoring or empowering the regulatory component of the immune system has gained substantial traction, as it may provide an alternative approach to the manipulation of the effector component and could even be used as a primary therapeutic approach for autoimmune and transplantation-related diseases, as well as cancer.

In most organ-specific and systemic autoimmune diseases, the numbers of $\mathrm{T}_{\text {reg }}$ cells and their functional status are not universally decreased, suggesting that, although $\mathrm{T}_{\text {reg }}$ cell malfunction is dominant and drives disease pathology in certain patients, it does not do so in others. Simply speaking, any trial attempting to empower $\mathrm{T}_{\text {reg }}$ cells in all patients who present with an autoimmune disease may be subject to type 2 (false negative) errors, and a treatment that could be beneficial for a subset of patients could be erroneously rejected. A cohort of patients who have a deficit in $\mathrm{T}_{\text {reg }}$ cell number should be identified and $\mathrm{T}_{\text {reg }}$ cell-enhancing medications should be administered to only these patients. Similarly, elimination of $\mathrm{T}_{\text {reg }}$ cells in patients with cancer may benefit only those in whom $\mathrm{T}_{\text {reg }}$ cells outnumber $\mathrm{T}_{\text {eff }}$ cells in the tumour.

Expansion of $\mathrm{T}_{\text {reg }}$ cells ex vivo before reinfusion has been considered extensively in early clinical trials. This particular approach is confounded by a number of problems inherent to cell therapies or specifically to $\mathrm{T}_{\text {reg }}$ cells. Cell therapy, outside a research setting or a specialized centre, presents myriad logistical and financial burdens that may preclude its applicability to common 
autoimmune diseases or patients receiving transplant organs. $\mathrm{T}_{\text {reg }}$ cells may be expanded ex vivo, but their instability may be a serious limiting factor. After being expanded in vitro in high concentrations of IL-2, they will probably die after being infused into patients, where the concentrations of IL-2 are low. Methods to stabilize $\mathrm{T}_{\text {reg }}$ cells - for example, by increasing the methylation status of the FOXP3 locus or increasing the effect of FOXP3 on its target genes (for example, by suppressing special AT-rich sequence-binding protein 1 (SATB1), a genome organizer that is expressed in T cells and regulates chromatin structure and gene expression ${ }^{298}$ ) should be explored.

Although it has not been documented in patients, one possible issue with $\mathrm{T}_{\text {reg }}$ cell therapy is that the newly expanded $\mathrm{T}_{\text {reg }}$ cells in the periphery easily convert to effector cells, and if the percentage of these cells is high, there may be a flare of the inflammatory process in the individual recipient.

The possibility of further engineering $\mathrm{T}_{\text {reg }}$ cells (transfected with the FOXP3 gene) with TCRs that recognize known antigens or autoantigens and are fused to the intracellular domains of signalling proteins that are able to confer a regulatory phenotype is tantalizing. This approach could be of great value in patients with haemophilia or receiving transplant organs. It could be equally valuable to patients with organ-specific autoimmune diseases in whom one or a few culprit autoantigens are known to be involved, but this approach would be more cumbersome in patients with systemic autoimmune diseases. Again, this approach should be limited to patients in whom a $\mathrm{T}_{\text {reg }}$ cell numerical deficiency drives autoimmune pathology.

Expansion or empowerment of $\mathrm{T}_{\text {reg }}$ cells in vivo is more realistic and, if successful, could benefit many patients whose care is not linked to major centres. Low-dose IL-2 has been claimed to be helpful in uncontrolled studies,

\section{Box $2 \mid T_{\text {reg }}$ cells in wound repair and tissue regeneration}

Lymphocytes, including $\mathrm{CD}^{+}$and $\mathrm{CD} 8^{+} \mathrm{T}$ cells, are recruited to sites of inflammation and promote tissue injury. Regulatory $\mathrm{T}\left(\mathrm{T}_{\mathrm{reg}}\right)$ cells also accumulate in sites of inflammation, such as the skeletal muscle after injury, where they promote the switch from an inflammatory to a regenerative state and persist for at least $1 \mathrm{month}^{308}$. These $\mathrm{T}_{\text {reg }}$ cells express high levels of amphiregulin (AREG), an epithelial growth factor (EGF) family protein, which promotes muscle regeneration by activating the EGF receptor (EGFR) signalling axis ${ }^{308}$. $T_{\text {reg }}$ cells that express AREG can also protect lungs from infection-induced damage ${ }^{309}$. AREG controls the immune response by regulating $\mathrm{T}_{\text {reg }}$ cell function ${ }^{310}$. Involvement of AREG-EGFR signals in $\mathrm{T}_{\text {reg }}$ cell-mediated tissue regeneration is also observed in skin injury and promotes wound healing ${ }^{311,312}$.

Furthermore, skin $\mathrm{T}_{\text {reg }}$ cells preferentially reside close to hair follicle stem cells (HFSCs) and help HFSC-mediated hair regeneration ${ }^{313}$. Paracrine effects of $\mathrm{T}_{\text {reg }}$ cells were also shown to promote cardiomyocyte proliferation during pregnancy and after myocardial infarction $^{314}$.

Thelper $1\left(T_{H} 1\right)$ cells and $T_{H} 17$ cells have been shown to promote neuroinflammation, but remyelination is compromised in the absence of lymphocytes ${ }^{315}$, indicating that some lymphocytes are pro-regenerative in the brain. Indeed, $\mathrm{T}_{\text {reg }}$ cells directly promote remyelination independently of immunomodulation, and when $\mathrm{T}_{\text {reg }}$ cells are deleted, the process is impaired ${ }^{316}$.

The ability of $\mathrm{T}_{\text {reg }}$ cells to contribute to tissue repair expands their importance far beyond controlling the immune response and suggests that these cells can be used to reverse advanced tissue damage caused by immune or non-immune processes. and ongoing controlled studies should determine the clinical usefulness of this drug. There are a number of issues that may surface with administering low-dose IL-2 to patients with autoimmune diseases. First, the short half-life of IL-2 (the drug itself or its biological effect), which may be even shorter in patients with autoimmune diseases, could be problematic. Next, the therapeutic window between low-dose and high-dose IL-2 is very narrow, and this may cause side effects in some patients. Last, but equally important, is the possibility that IL-2 does not elicit a signalling response in $\mathrm{T}_{\text {reg }}$ cells from patients with autoimmune diseases as it does in healthy individuals. The problem of the short half-life of IL-2 has been recognized, and a number of fusion molecules have been developed. The poor IL-2-elicited signalling response has been largely ignored, but approaches that involve co-engagement of other surface molecules (for example, SLAMF3 (also known as LY9)) may offer ways to restore the defective generation of phosphorylated STAT5. In this article, we have discussed molecules, such as mTOR, that limit $\mathrm{T}_{\text {reg }}$ cell function and can be targeted with adjuvant drugs to IL-2 to increase the function of $\mathrm{T}_{\text {reg }}$ cells. PP2A activity enhancers (such as ceramide) may increase PP2A activity, which is needed for the proper function of $\mathrm{T}_{\text {reg }}$ cells.

The challenges to suppressing $\mathrm{T}_{\text {reg }}$ cells in tumours loom larger than those to expand their function. Obviously, we need to better understand the nature and development of $\mathrm{T}_{\text {reg }}$ cells in tumours. Some of the obvious big questions are what molecules enable $\mathrm{T}_{\text {reg }}$ cells to enter tumours, do tumour cells or the tumour microenvironment further propagate $\mathrm{T}_{\text {reg }}$ cell stability and function, and do $\mathrm{T}_{\text {reg }}$ cells develop from naive $\mathrm{CD} 4^{+} \mathrm{T}$ cells after they are inside the tumour. Current technologies involving singlecell RNA sequencing of tumour cells and infiltrating inflammatory cells are expected to provide these muchneeded insights. Systemic inhibition of $\mathrm{T}_{\text {reg }}$ cells likely carries the risks of not depleting $\mathrm{T}_{\text {reg }}$ cells in the tumour and of unleashing an autoinflammatory response similar to those already reported in patients receiving checkpoint inhibitors. Biologics directed against chemokines and/or their receptors that enable $\mathrm{T}_{\text {reg }}$ cell entry into the tumour should gain traction. Alternatively, approaches to deliver $\mathrm{T}_{\text {reg }}$ cell-disabling or $\mathrm{T}_{\text {reg }}$ cell-depleting biologics to the tumour in a specific manner could be therapeutically important.

An exciting new concept comes from data that detail the role of $\mathrm{T}_{\text {reg }}$ cells present in organs targeted by the inflammatory response and their unexpected ability to repair damaged tissues (BOX 2). Although purely speculative at this point, it is exciting to consider delivering engineered $\mathrm{T}_{\text {reg }}$ cells to the kidneys of patients with lupus nephritis or to the pancreas of patients with T1D.

Although expanding and empowering $\mathrm{T}_{\text {reg }}$ cells to treat autoimmune disease are actively being explored, suppressing them in cancer is still in the nascent stage. The expected reward if $\mathrm{T}_{\text {reg }}$ cells can be manipulated is high given the currently used side-effect-laden indiscriminate immunosuppressant drugs in the treatment of autoimmune diseases and the toxic drugs used in patients with cancer. 
1. Brunkow, M. E. et al. Disruption of a new forkhead/ winged-helix protein, scurfin, results in the fatal lymphoproliferative disorder of the scurfy mouse. Nat. Genet. 27, 68-73 (2001).

2. Fontenot, J. D., Gavin, M. A. \& Rudensky, A. Y. Foxp3 programs the development and function of CD4 + CD25 + regulatory T cells. Nat. Immunol. 4, 330-336 (2003)

3. Wildin, R. S. et al. X-Linked neonatal diabetes mellitus, enteropathy and endocrinopathy syndrome is the human equivalent of mouse scurfy. Nat. Genet. 27 18-20 (2001).

4. Bennett, C. L. et al. The immune dysregulation, polyendocrinopathy, enteropathy, X-linked syndrome (IPEX) is caused by mutations of FOXP3. Nat. Genet. 27, 20-21 (2001).

5. June, C. H. Adoptive T cell therapy for cancer in the clinic. J. Clin. Invest. 117, 1466-1476 (2007).

6. Hoffmann, P. et al. Isolation of CD4 + CD25+ regulatory T cells for clinical trials. Biol. Blood Marrow Transplant. 12, 267-274 (2006).

7. Wright, G. P. et al. Adoptive therapy with redirected primary regulatory $\mathrm{T}$ cells results in antigen-specific suppression of arthritis. Proc. Natl Acad. Sci. USA 106, 19078-19083 (2009).

8. Matsuoka, K. et al. Low-dose interleukin-2 therapy restores regulatory $\mathrm{T}$ cell homeostasis in patients with chronic graft-versus-host disease. Sci. Transl Med. 5, 179ra43 (2013)

9. Saadoun, D. et al. Regulatory T cell responses to lowdose interleukin-2 in HCV-induced vasculitis. N. Engl. J. Med. 365, 2067-2077 (2011) This is one of the first studies to show that low-dose IL-2 can produce clinical benefit by expanding $\mathbf{T}_{\text {reg }}$ cells.

10. Klatzmann, D. \& Abbas, A. K. The promise of lowdose interleukin-2 therapy for autoimmune and inflammatory diseases. Nat. Rev. Immunol. 15, 283-294 (2015).

11. Jonuleit, $\mathrm{H}$. et al. Identification and functional characterization of human CD4(+)CD25(+) T cells with regulatory properties isolated from peripheral blood. J. Exp. Med. 193, 1285-1294 (2001).

12. Piccirillo, C. A. \& Shevach, E. M. Naturally-occurring CD4 + CD25 + immunoregulatory T cells: central players in the arena of peripheral tolerance. Semin Immunol. 16, 81-88 (2004).

13. Liu, W. et al. CD127 expression inversely correlates with FoxP3 and suppressive function of human CD4 T reg cells. J. Exp. Med. 203, 1701-1711 (2006).

14. Morgan, M. E. et al. Expression of FOXP3 mRNA is not confined to CD4 + CD25 + T regulatory cells in humans. Hum. Immunol. 66, 13-20 (2005).

15. Gavin, M. A. et al. Single-cell analysis of normal and FOXP3-mutant human T cells: FOXP3 expression without regulatory T cell development. Proc. Nat Acad. Sci. USA 103, 6659-6664 (2006).

16. Allan, S. E. et al. Activation-induced FOXP3 in human $T$ effector cells does not suppress proliferation or cytokine production. Int. Immunol. 19, 345-354 (2007).

17. Khattri, R., Cox, T., Yasayko, S. A. \& Ramsdell, F. An essential role for Scurfin in CD4 + CD25 + T regulatory cells. Nat. Immunol. 4, 337-342 (2003).

18. Hori, S., Nomura, T. \& Sakaguchi, S. Control of regulatory $\mathrm{T}$ cell development by the transcription factor Foxp3. Science 299, 1057-1061 (2003).

19. Omenetti, S. \& Pizarro, T. T. The Treg/Th 17 axis: a dynamic balance regulated by the gut microbiome. Front. Immunol. 6, 639 (2015).

20. Lio, C. W. \& Hsieh, C. S. A two-step process for thymic regulatory T cell development. Immunity 28, 100-11 (2008).

21. Burchill, M. A. et al. Linked T cell receptor and cytokine signaling govern the development of the regulatory T cell repertoire. Immunity 28, 112-121 (2008).

22. Long, M., Park, S. G., Strickland, I., Hayden, M. S. \& Ghosh, S. Nuclear factor-kappaB modulates regulatory $\mathrm{T}$ cell development by directly regulating expression of Foxp3 transcription factor. Immunity 31, 921-931 (2009).

23. Luo, C. T. \& Li, M. O. Transcriptional control of regulatory $\mathrm{T}$ cell development and function. Trends Immunol. 34, 531-539 (2013).

24. Li, X., Liang, Y., LeBlanc, M., Benner, C. \& Zheng, Y. Function of a Foxp3 cis-element in protecting regulatory T cell identity. Cell 158, 734-748 (2014).

25. Zheng, Y. et al. Role of conserved non-coding DNA elements in the Foxp3 gene in regulatory $T$ cell fate. Nature 463, 808-812 (2010).
26. Mahmud, S. A. et al. Costimulation via the tumornecrosis factor receptor superfamily couples TCR signal strength to the thymic differentiation of regulatory T cells. Nat. Immunol. 15, 473-481 (2014).

27. Huynh, A. et al. Control of PI(3) kinase in Treg cells maintains homeostasis and lineage stability. Nat. Immunol. 16, 188-196 (2015).

28. Marie, J. C., Liggitt, D. \& Rudensky, A. Y. Cellular mechanisms of fatal early-onset autoimmunity in mice with the T cell-specific targeting of transforming growth factor-beta receptor. Immunity 25, 441-454 (2006)

29. Konkel, J. E., Jin, W., Abbatiello, B., Grainger, J. R. \& Chen, W. Thymocyte apoptosis drives the intrathymic generation of regulatory T cells. Proc. Natl Acad. Sci. USA 111, E465-E473 (2014).

30. Chen, W. et al. Conversion of peripheral CD $4+C D 25$ naive $T$ cells to $C D 4+C D 25$ + regulatory $T$ cells by TGF-beta induction of transcription factor Foxp3. J. Exp. Med. 198, 1875-1886 (2003).

31. Chen, W. \& Konkel, J. E. Development of thymic Foxp3 $(+)$ regulatory T cells: TGF- $\beta$ matters Eur. J. Immunol. 45, 958-965 (2015)

32. Wing, K. et al. CTLA-4 control over Foxp3 + regulatory T cell function. Science 322, 271-275 (2008)

33. Qureshi, O. S. et al. Trans-endocytosis of CD80 and CD86: a molecular basis for the cell-extrinsic function of CTLA-4. Science 332, 600-603 (2011).

34. Liang, B. et al. Regulatory $\mathrm{T}$ cells inhibit dendritic cells by lymphocyte activation gene-3 engagement of MHC class II. J. Immunol. 180, 5916-5926 (2008)

35. Sarris, M., Andersen, K. G., Randow, F., Mayr, L. \& Betz, A. G. Neuropilin-1 expression on regulatory $\mathrm{T}$ cells enhances their interactions with dendritic cells during antigen recognition. Immunity 28, 402-413 (2008)

36. Borsellino, G. et al. Expression of ectonucleotidase CD39 by Foxp3 + Treg cells: hydrolysis of extracellular ATP and immune suppression. Blood 110 1225-1232 (2007).

37. Kobie, J. J. et al. T regulatory and primed uncommitted CD4 T cells express CD73, which suppresses effector CD4 T cells by converting 5 '-adenosine monophosphate to adenosine. J. Immunol. 177, 6780-6786 (2006).

38. Deaglio, S. et al. Adenosine generation catalyzed by CD39 and CD73 expressed on regulatory T cells mediates immune suppression. J. Exp. Med. 204 1257-1265 (2007)

39. Chinen, T. et al. An essential role for the IL-2 receptor in Treg cell function. Nat. Immunol. 17, 1322-1333 (2016).

40. Malek, T. R. et al. IL-2 family of cytokines in $T$ regulatory cell development and homeostasis. J. Clin. Immunol. 28, 635-639 (2008).

41. Pandiyan, P., Zheng, L., Ishihara, S., Reed, J. \& Lenardo, M. J. CD4 + CD25 + Foxp3 + regulatory $\mathrm{T}$ cells induce cytokine deprivation-mediated apoptosis of effector CD4 + T cells. Nat. Immunol. 8 , 1353-1362 (2007)

42. Gondek, D. C., Lu, L. F., Quezada, S. A., Sakaguchi, S $\&$ Noelle, R. J. Cutting edge: contact-mediated suppression by CD4 + CD25 + regulatory cells involves a granzyme B-dependent, perforin-independent mechanism. J. Immunol. 174, 1783-1786 (2005).

43. Cao, X. et al. Granzyme B and perforin are important for regulatory T cell-mediated suppression of tumor clearance. Immunity 27, 635-646 (2007).

44. Feuerer, M. et al. Genomic definition of multiple ex vivo regulatory T cell subphenotypes. Proc. Nat Acad. Sci. USA 107, 5919-5924 (2010).

45. Smigiel, K. S. et al. CCR7 provides localized access to L-2 and defines homeostatically distinct regulatory T cell subsets. J. Exp. Med. 211, 121-136 (2014).

46. Bergot, A.-S. et al. TCR sequences and tissue distribution discriminate the subsets of naïve and activated/memory Treg cells in mice. Eur. J. Immunol. 45, 1524-1534 (2015).

47. Sugiyama, D. et al. Anti-CCR4 mAb selectively depletes effector-type FoxP3 + CD4 + regulator $\mathrm{T}$ cells, evoking antitumor immune responses in humans. Proc. Natl Acad. Sci. USA 110 17945-17950 (2013).

48. Koch, M. A. et al. T-Bet(+) Treg cells undergo abortive Th 1 cell differentiation due to impaired expression of IL-12 receptor $\beta 2$. Immunity 37 , 501-510 (2012).

49. Wang, Y., Su, M. A. \& Wan, Y. Y. An essential role of the transcription factor CATA-3 for the function of regulatory T cells. Immunity 35, 337-348 (2011)
50. Chaudhry, A et al CD4 + regulatory T cells control TH1 7 responses in a Stat3-dependent manner Science 326, 986-991 (2009)

This is one of the first studies to introduce the concept that $\mathrm{T}_{\text {reg }}$ cells express the same transcription factors as the cells they are supposed to suppress.

51. Linterman, M. A. et al. Foxp3 + follicular regulatory $T$ cells control the germinal center response. Nat. Med. 17, 975-982 (2011).

52. Levine, A. G. et al. Stability and function of regulatory T cells expressing the transcription factor T-bet. Nature 546, 421-425 (2017).

53. Levine, A. G., Arvey, A., Jin, W. \& Rudensky, A. Y. Continuous requirement for the TCR in regulatory T cell function. Nat. Immunol. 15, 1070-1078 (2014).

54. Smigiel, K. S., Srivastava, S., Stolley, J. M. \& Campbell, D. J. Regulatory T cell homeostasis: steadystate maintenance and modulation during inflammation. Immunol. Rev. 259, 40-59 (2014).

55. Cheng, G. et al. IL-2 receptor signaling is essential for the development of KIrg $1+$ terminally differentiated T regulatory cells. J. Immunol. 189, 1780-1791 (2012).

56. Pierson, W. et al. Antiapoptotic Mcl-1 is critical for the survival and niche-filling capacity of Foxp3(+) regulatory T cells. Nat. Immunol. 14, 959-965 (2013).

57. Yu, A., Zhu, L., Altman, N. H. \& Malek, T. R. A low interleukin-2 receptor signaling threshold supports the development and homeostasis of $\mathrm{T}$ regulatory cells. Immunity 30, 204-217 (2009).

58. Castro, I., Yu, A., Dee, M. J. \& Malek, T. R. The basis of distinctive IL-2- and IL-15-dependent signaling: weak CD122-dependent signaling favors CD8 + T centralmemory cell survival but not $\mathrm{T}$ effector-memory cell development. J. Immunol. 187, 5170-5182 (2011).

59. Saxton, R. A. \& Sabatini, D. M. mTOR signaling in growth, metabolism, and disease. Cell 168, 960-976 (2017).

60. Perl, A. Activation of mTOR (mechanistic target of rapamycin) in rheumatic diseases. Nat. Rev. Rheumatol. 12, 169-182 (2016)

61. Delgoffe, G. M. et al. The kinase mTOR regulates the differentiation of helper T cells through the selective activation of signaling by mTORC 1 and $\mathrm{mTORC} 2$. Nat. Immunol. 12, 295-303 (2011).

62. Zeng, $\mathrm{H}$. et al. mTORC1 couples immune signals and metabolic programming to establish T(reg)-cell function. Nature 499, 485-490 (2013).

63. Michalek, R. D. et al. Cutting edge: distinct glycolytic and lipid oxidative metabolic programs are essential for effector and regulatory CD4 + T cell subsets. J. Immunol. 186, 3299-3303 (2011).

64. Coe, D. J., Kishore, M. \& Marelli-Berg, F. Metabolic regulation of regulatory $T$ cell development and function. Front. Immunol. 5, 590 (2014)

65. Powell, J. D., Pollizzi, K. N., Heikamp, E. B. \& Horton, M. R. Regulation of immune responses by mTOR. Annu. Rev. Immunol. 30, 39-68 (2012).

66. Walsh, P. T. et al. PTEN inhibits IL-2 receptor-mediated expansion of CD4 + CD25 + Tregs. J. Clin. Invest. 116, 2521-2531 (2006).

67. Delgoffe, G. M. et al. Stability and function of regulatory $T$ cells is maintained by a neuropilin-1-semaphorin-4a axis. Nature 501, 252-256 (2013)

This paper shows that the immune cell-expressed ligand SEMA4A and the $T_{\text {reg }}$ cell-expressed receptor NRP1 interact to potentiate $T_{\text {reg }}$ cell function and survival.

68. Apostolidis, S. A. et al. Phosphatase PP2A is requisite for the function of regulatory T cells. Nat. Immunol. 17, 556-564 (2016)

This paper shows that PP2A, a serine/threonine phosphatase, is important for the proper function of $T_{\text {reg }}$ cells and that its absence leads to extensive autoimmunity and multiple organ inflammation.

69. Torgerson, T. R. \& Ochs, H. D. Immune dysregulation, polyendocrinopathy, enteropathy, X-linked: forkhead box protein 3 mutations and lack of regulatory T cells. J. Allergy Clin. Immunol. 120, 744-750 (2007).

70. Malek, T. R. \& Bayer, A. L. Tolerance, not immunity, crucially depends on IL-2. Nat. Rev. Immunol. 4 665-674 (2004)

71. Malek, T. R. The biology of interleukin-2. Annu. Rev. Immunol. 26, 453-479 (2008)

72. Bernasconi, A. et al. Characterization of immunodeficiency in a patient with growth hormone insensitivity secondary to a novel STAT5 $\mathrm{b}$ gene mutation. Pediatrics 118, e 1584-e1592 (2006). 
73. Nadeau, K., Hwa, V. \& Rosenfeld, R. G. STAT5b deficiency: an unsuspected cause of growth failure, immunodeficiency, and severe pulmonary disease. J. Pediatr. 158, 701-708 (2011).

74. Schubert, D. et al. Autosomal dominant immune dysregulation syndrome in humans with CTLA4 mutations. Nat. Med. 20, 1410-1416 (2014).

75. Charbonnier, L. M. et al. Regulatory T cell deficiency and immune dysregulation, polyendocrinopathy, enteropathy, X-linked-like disorder caused by loss-of-function mutations in LRBA. J. Allergy Clin. Immunol. 135, 217-227 (2015)

76. Ohl, K. \& Tenbrock, K. Regulatory T cells in systemic lupus erythematosus. Eur. J. Immunol. 45, 344-355 (2015).

77. Lyssuk, E. Y., Torgashina, A. V., Soloviev, S. K Nassonov, E. L. \& Bykovskaia, S. N. Reduced number and function of CD4 + CD25highFoxP3 + regulatory $T$ cells in patients with systemic lupus erythematosus. Adv. Exp. Med. Biol. 601, 113-119 (2007).

78. Bonelli, M. et al. Quantitative and qualitative deficiencies of regulatory T cells in patients with systemic lupus erythematosus (SLE). Int. Immunol. 20 861-868 (2008)

79. Venigalla, R. K. C. et al. Reduced CD4 +,CD25- T cell sensitivity to the suppressive function of CD4 +, CD25high, CD127 - /low regulatory T cells in patients with active systemic lupus erythematosus. Arthritis Rheum. 58, 2120-2130 (2008).

80. Miyara, M. et al. Functional delineation and differentiation dynamics of human CD4 + T cells expressing the FoxP3 transcription factor. Immunity 30, 899-911 (2009).

81. Comte, D. et al. Brief report: CD4 + T cells from patients with systemic lupus erythematosus respond poorly to exogenous interleukin-2. Arthritis Rheumatol. 69, 808-813 (2017).

82. Afeltra, A. et al. The involvement of T regulatory lymphocytes in a cohort of lupus nephritis patients: a pilot study. Intern. Emerg. Med. 10, 677-683 (2015).

83. Marwaha, A. K. et al. Cutting edge: increased IL-17-secreting T cells in children with new-onset type 1 diabetes. J. Immunol. 185, 3814-3818 (2010).

84. Long, S. A. et al. Defects in IL-2R signaling contribute to diminished maintenance of FOXP3 expression in CD4(+)CD25(+) regulatory T cells of type 1 diabetic subjects. Diabetes 59, 407-415 (2010)

85. Schneider, A. et al. The effector T cells of diabetic subjects are resistant to regulation via CD4 + FOXP3 + regulatory T cells. J. Immunol. 181 7350-7355 (2008).

86. Harden, J. L., Krueger, J. G. \& Bowcock, A. M. The immunogenetics of psoriasis: a comprehensive review. J. Autoimmun. 64, 66-73 (2015)

87. Soler, D. C. et al. Psoriasis patients exhibit impairment of the high potency CCR5 (+) T regulatory cell subset. Clin. Immunol. 149, 111-118 (2013).

88. Sugiyama, $\mathrm{H}$. et al. Dysfunctional blood and target tissue CD4 + CD25high regulatory T cells in psoriasis: mechanism underlying unrestrained pathogenic effector T cell proliferation. J. Immunol. 174, 164-173 (2005)

89. Zhang, $\mathrm{K}$. et al. Functional characterization of CD $4+C D 25$ + regulatory T cells differentiated in vitro from bone marrow-derived haematopoietic cells of psoriasis patients with a family history of the disorder Br. J. Dermatol. 158, 298-305 (2008).

90. Bovenschen, H. J. et al. Foxp3 + regulatory T cells of psoriasis patients easily differentiate into IL-17A-producing cells and are found in lesional skin. J. Invest. Dermatol. 131, 1853-1860 (2011).

91. Balandina, A., Lecart, S., Dartevelle, P., Saoudi, A. \& Berrih-Aknin, S. Functional defect of regulatory CD4 $(+) C D 25+T$ cells in the thymus of patients with autoimmune myasthenia gravis. Blood 105, 735-74 (2005).

92. Thiruppathi, M. et al. Impaired regulatory function in circulating CD4(+)CD25(high)CD 127(low/-) T cells in patients with myasthenia gravis. Clin. Immunol. 145, 209-223 (2012)

93. Alahgholi-Hajibehzad, M. et al. Regulatory function of CD4 + CD25 + + T cells in patients with myasthenia gravis is associated with phenotypic changes and STAT5 signaling: 1,25-Dihydroxyvitamin D3 modulates the suppressor activity. J. Neuroimmunol. 281, 51-60 (2015)

94. Renton, A. E. et al. A genome-wide association study of myasthenia gravis. JAMA Neurol. 72, 396-404 (2015).
95. Masuda, M. et al. Clinical implication of peripheral CD4 + CD25 + regulatory T cells and Th1 7 cells in myasthenia gravis patients. J. Neuroimmunol. 225, 123-131 (2010).

96. Makita, S. et al. CD4 + CD25bright T cells in human intestinal lamina propria as regulatory cells. J. Immunol. 173, 3119-3130 (2004).

97. Maul, J. et al. Peripheral and intestinal regulatory CD4 + CD25(high) T cells in inflammatory bowel disease. Gastroenterology 128, 1868-1878 (2005)

98. Uhlig, H. H. et al. Characterization of Foxp3 + CD4 + CD25 + and IL-10-secreting $\mathrm{CD} 4+\mathrm{CD} 25+\mathrm{T}$ cells during cure of colitis. J. Immunol. 177, 5852-5860 (2006)

99. Monteleone, G. et al. Blocking Smad7 restores TGF-beta1 signaling in chronic inflammatory bowel disease. J. Clin. Invest. 108, 601-609 (2001)

100. Geremia, A., Biancheri, P., Allan, P., Corazza, G. R. \& Di Sabatino, A. Innate and adaptive immunity in inflammatory bowel disease. Autoimmun. Rev. 13, 3-10 (2014).

101. Agus, A., Planchais, J. \& Sokol, H. Gut microbiota regulation of tryptophan metabolism in health and disease. Cell Host Microbe 23, 716-724 (2018).

102. McFarland, H. F. \& Martin, R. Multiple sclerosis: a complicated picture of autoimmunity. Nat. Immunol. 8, 913-919 (2007)

103. Liu, Y., Teige, I., Birnir, B. \& Issazadeh-Navikas, S Neuron-mediated generation of regulatory T cells from encephalitogenic T cells suppresses EAE. Nat. Med. 12, 518-525 (2006).

104. Korn, T. et al. Myelin-specific regulatory T cells accumulate in the CNS but fail to control autoimmune inflammation. Nat. Med. 13, 423-431 (2007).

105. Noori-Zadeh, A. et al. Regulatory T cell number in multiple sclerosis patients: a meta-analysis. Mult. Scler. Relat. Disord. 5, 73-76 (2016)

106. Viglietta, V., Baecher-Allan, C., Weiner, H. L. \& Hafler, D. A. Loss of functional suppression by CD4 + CD25 + regulatory T cells in patients with multiple sclerosis. J. Exp. Med. 199, 971-979 (2004).

107. Lechler, R. I., Garden, O. A. \& Turka, L. A The complementary roles of deletion and regulation in transplantation tolerance. Nat. Rev. Immunol. 3 , 147-158 (2003)

108. Wood, K. J. \& Sakaguchi, S. Regulatory T cells in transplantation tolerance. Nat. Rev. Immunol. 3 , 199-210 (2003)

109. Jiang, S., Herrera, O. \& Lechler, R. I. New spectrum of allorecognition pathways: implications for graft rejection and transplantation tolerance. Curr. Opin Immunol. 16, 550-557 (2004)

110. Lee, K., Nguyen, V., Lee, K. M., Kang, S. M. \& Tang, Q. Attenuation of donor-reactive $\mathrm{T}$ cells allows effective control of allograft rejection using regulatory $T$ cell therapy. Am. J. Transplant. 14, 27-38 (2014).

111. Koga, T. et al. CaMK4-dependent activation of AKT/ mTOR and CREM- $\alpha$ underlies autoimmunity associated Th 17 imbalance. J. Clin. Invest. 124 2234-2245 (2014)

112. Koga, T., Ichinose, K., Mizui, M., Crispin, J. C. \& Tsokos, G. C. Calcium/calmodulin-dependent protein kinase IV suppresses IL-2 production and regulatory T cell activity in lupus. J. Immunol. 189, 3490-3496 (2012)

113. Budhu, S. et al. Blockade of surface-bound TGF-beta on regulatory $\mathrm{T}$ cells abrogates suppression of effector $\mathrm{T}$ cell function in the tumor microenvironment. Sci. Signal. 10, eaak9702 (2017).

114. Facciabene, A. et al. Tumour hypoxia promotes tolerance and angiogenesis via CCL28 and T(reg) cells. Nature 475, 226-230 (2011).

This study shows that tumour hypoxia promotes the recruitment of $T_{\text {r }}$ cells through the induction of expression of the chemokine CCL28, which, in turn, promotes tumour tolerance and angiogenesis.

115. Facciabene, A., Motz, G. T. \& Coukos, G. T-Regulatory cells: key players in tumor immune escape and angiogenesis. Cancer Res. 72, 2162-2171 (2012).

116. van der Stegen, S. J. C., Hamieh, M. \& Sadelain, M. The pharmacology of second-generation chimeric antigen receptors. Nat. Rev. Drug Discov. 14 499-509 (2015)

117. Whiteside, T. L. The role of regulatory T cells in cancer immunology. Immunotargets Ther. 4, 159-171 (2015)

118. Halvorsen, E. C., Mahmoud, S. M. \& Bennewith, K. L. Emerging roles of regulatory $T$ cells in tumour progression and metastasis. Cancer Metastasis Rev. 33, 1025-1041 (2014).
119. Valzasina, B., Piconese, S., Guiducci, C \& Colombo, M. P. Tumor-induced expansion of regulatory $T$ cells by conversion of CD $4+C D 25$ lymphocytes is thymus and proliferation independent. Cancer Res. 66, 4488-4495 (2006).

120. Curti, A. et al. Modulation of tryptophan catabolism by human leukemic cells results in the conversion of CD25- into CD25 + T regulatory cells. Blood 109, 2871-2877 (2007).

121. Zhou, G. \& Levitsky, H. I. Natural regulatory T cells and de novo-induced regulatory $T$ cells contribute independently to tumor-specific tolerance. J. Immunol. 178, 2155-2162 (2007)

122. Hindley, J. P. et al. Analysis of the T cell receptor repertoires of tumor-infiltrating conventional and regulatory $\mathrm{T}$ cells reveals no evidence for conversion in carcinogen-induced tumors. Cancer Res. 71, 736-746 (2011)

123. Plitas, G. et al. Regulatory T cells exhibit distinct features in human breast cancer. Immunity $\mathbf{4 5}$ 1122-1134 (2016)

124. Malchow, S. et al. Aire-dependent thymic developmen of tumor-associated regulatory T cells. Science 339 1219-1224 (2013).

125. Darrasse-Jeze, G. et al. Tumor emergence is sensed by self-specific CD44hi memory Tregs that create a dominant tolerogenic environment for tumors in mice. J. Clin. Invest. 119, 2648-2662 (2009).

126. Angelin, A. et al. Foxp3 reprograms T cell metabolism to function in low-glucose, high-lactate environments. Cell Metab. 25, 1282-1293 (2017). This study presents the metabolic cascades that characterize $\mathrm{T}_{\text {reg }}$ cells.

127. Wang, H., Franco, F. \& Ho, P. C. Metabolic regulation of Tregs in cancer: opportunities for immunotherapy. Trends Cancer 3, 583-592 (2017).

128. Mezrich, J. D. et al. An interaction between kynurenine and the aryl hydrocarbon receptor can generate regulatory T cells. J. Immunol. 185 3190-3198 (2010)

129. Naganuma, M. et al. Cutting edge: critical role for A2A adenosine receptors in the T cell-mediated regulation of colitis. J. Immunol. 177, 2765-2769 (2006).

130. Facciabene, A., Santoro, S. \& Coukos, G. Know thy enemy: why are tumor-infiltrating regulatory $\mathrm{T}$ cells so deleterious? Oncoimmunology 1, 575-577 (2012)

131. Shang, B., Liu, Y., Jiang, S. J. \& Liu, Y. Prognostic value of tumor-infiltrating FoxP3 + regulatory T cells in cancers: a systematic review and meta-analysis. Sci. Rep. 5, 15179 (2015).

132. Bates, G. J. et al. Quantification of regulatory T cells enables the identification of high-risk breast cance patients and those at risk of late relapse. J. Clin. Oncol. 24, 5373-5380 (2006).

133. Tan, W. et al. Tumour-infiltrating regulatory T cells stimulate mammary cancer metastasis through RANKL-RANK signalling. Nature 470, 548-553 (2011).

134. Ward-Hartstonge, K. A. \& Kemp, R. A. Regulatory $T$ cell heterogeneity and the cancer immune response. Clin. Transl Immunol. 6, e154 (2017)

135. Saito, T. et al. Two FOXP3 (+)CD4(+) T cell subpopulations distinctly control the prognosis of colorectal cancers. Nat. Med. 22, 679-684 (2016). This study shows that the presence of FOXP3 ${ }^{\text {low }} \mathrm{T}$ cells in colorectal cancer tissues indicates a significantly better prognosis than the presence of predominantly FOXP3 ${ }^{\text {high }} \mathbf{T}_{\text {reg }}$ cells. This study has brought attention to the subpopulation of $T_{\text {reg }}$ cells with low FOXP3 expression, which of $T_{\text {reg }}$ cells with low FOXP3 expression,
should not be deleted when applying immunotherapeutic regimens.

136. Delacher, M. et al. Genome-wide DNA-methylation landscape defines specialization of regulatory $T$ cells in tissues. Nat. Immunol. 18, 1160-1172 (2017)

137. Trzonkowski, P. et al. Hurdles in therapy with regulatory T cells. Sci. Transl Med. 7, 304ps18 (2015)

138. Taylor, P. A., Lees, C. J. \& Blazar, B. R. The infusion of ex vivo activated and expanded CD4(+)CD25(+) immune regulatory cells inhibits graft-versus-hos disease lethality. Blood 99, 3493-3499 (2002).

139. Cohen, J. L., Trenado, A., Vasey, D., Klatzmann, D. \& Salomon, B. L. CD4(+)CD25(+) immunoregulatory T cells: new therapeutics for graft-versus-host disease. J. Exp. Med. 196, 401-406 (2002).

140. Trzonkowski, P. et al. First-in-man clinical results of the treatment of patients with graft versus host disease with human ex vivo expanded CD4 + CD25 + CD127regulatory cells. Clin. Immunol. 133, 22-26 (2009). 
141. Di lanni, M. et al. Tregs prevent GVHD and promote immune reconstitution in HLA-haploidentical transplantation. Blood 117, 3921-3928 (2011).

142. Brunstein, C. G. et al. Infusion of ex vivo expanded T regulatory cells in adults transplanted with umbilical cord blood: safety profile and detection kinetics. Blood 117, 1061-1070 (2011).

143. Juvet, S. C., Whatcott, A. G., Bushell, A. R. \& Wood, K. J. Harnessing regulatory T cells for clinical use in transplantation: the end of the beginning. Am. J. Transplant. 14, 750-763 (2014).

144. Stiller, C. et al. Cyclosporine for treatment of early type I diabetes: preliminary results. N. Engl. J. Med. 308, 1226-1227 (1983)

145. Bougneres, P. et al. Factors associated with early remission of type I diabetes in children treated with cyclosporine. N. Engl. J. Med. 318, 663-670 (1988).

146. Marek-Trzonkowska, N. et al. Administration of CD4 + CD25highCD 127- regulatory T cells preserves beta-cell function in type 1 diabetes in children Diabetes Care 35, 1817-1820 (2012).

147. Marek-Trzonkowska, N. et al. Therapy of type 1 diabetes with CD4(+)CD25(high)CD 127-regulatory $\mathrm{T}$ cells prolongs survival of pancreatic islets - results of one year follow-up. Clin. Immunol. 153, 23-30 (2014).

148. Bluestone, J. A. et al. Type 1 diabetes immunotherapy using polyclonal regulatory T cells. Sci. Transl Med. 7 . 315ra189 (2015).

149. Kim, H. P. \& Leonard, W. J. CREB/ATF-dependent $T$ cell receptor-induced FoxP3 gene expression: a role for DNA methylation. J. Exp. Med. 204, 1543-1551 (2007).

150. Ohkura, N. et al. T cell receptor stimulation-induced epigenetic changes and Foxp3 expression are independent and complementary events required for Treg cell development. Immunity 37, 785-799 (2012).

151. Ohkura, N., Kitagawa, Y. \& Sakaguchi, S. Development and maintenance of regulatory T cells. Immunity 38 414-423 (2013)

152. Yang, R. et al. Hydrogen sulfide promotes Tet1- and Tet2-mediated Foxp3 demethylation to drive regulatory $\mathrm{T}$ Cell differentiation and maintain immune homeostasis. Immunity 43, 251-263 (2015).

153. Gerriets, V. A. et al. Foxp3 and Toll-like receptor signaling balance Treg cell anabolic metabolism for suppression. Nat. Immunol. 17, 1459-1466 (2016).

154. Shrestha, S. et al. Treg cells require the phosphatase PTEN to restrain TH1 and TFH cell responses. Nat. Immunol. 16, 178-187 (2015).

155. Strauss, L., Czystowska, M., Szajnik, M. Mandapathil, M. \& Whiteside, T. L. Differential responses of human regulatory $T$ cells (Treg) and effector T cells to rapamycin. PLOS ONE 4, e5994 (2009).

156. Fernandez, D. R. et al. Activation of mammalian target of rapamycin controls the loss of TCRzeta in lupus T cells through HRES-1/Rab4-regulated lysosomal degradation. J. Immunol. 182, 2063-2073 (2009).

157. Kato, H. \& Perl, A. Mechanistic target of rapamycin complex 1 expands Th 17 and IL-4 + CD4-CD8double-negative $T$ cells and contracts regulatory $\mathrm{T}$ cells in systemic lupus erythematosus. J. Immunol. $192,4134-4144(2014)$

158. Warner, L. M., Adams, L. M. \& Sehgal, S. N. Rapamycin prolongs survival and arrests pathophysiologic changes in murine systemic lupus erythematosus. Arthritis Rheum. 37, 289-297 (1994).

159. Fernandez, D., Bonilla, E., Mirza, N., Niland, B. \& Perl, A. Rapamycin reduces disease activity and normalizes $\mathrm{T}$ cell activation-induced calcium fluxing in patients with systemic lupus erythematosus. Arthritis Rheum. 54, 2983-2988 (2006).

160. Oaks, Z. et al. Mitochondrial dysfunction in the liver and antiphospholipid antibody production precede disease onset and respond to rapamycin in lupus-prone mice. Arthritis Rheumatol 68, 2728-2739 (2016).

161. Canaud, G. et al. Inhibition of the mTORC pathway in the antiphospholipid syndrome. N. Engl. J. Med. 371 , 303-312 (2014)

162. Lai, Z. W. et al. Sirolimus in patients with clinically active systemic lupus erythematosus resistant to, or intolerant of, conventional medications: a single-arm, open-label, phase $1 / 2$ trial. Lancet 391, 1186-1196 (2018).

163. Tkachev, V. et al. Combined OX40L and mTOR blockade controls effector T cell activation while preserving Treg reconstitution after transplant. Sci. Transl Med. 9, eaan3085 (2017).
164. Taylor, P. A. et al. Insights into the mechanism of FTY720 and compatibility with regulatory T cells for the inhibition of graft-versus-host disease (GVHD) Blood 110, 3480-3488 (2007)

165. Chen, Y. B. et al. Increased Foxp3(+)Helios(+) regulatory $T$ cells and decreased acute graft-versushost disease after allogeneic bone marrow transplantation in patients receiving sirolimus and RGI-2001, an activator of invariant natural killer T cells. Biol. Blood Marrow Transplant. 23, 625-634 (2017).

166. Link, W. et al. Chemical interrogation of FOXO3a nuclear translocation identifies potent and selective inhibitors of phosphoinositide 3-kinases. J. Biol. Chem. 284, 28392-28400 (2009).

167. Liu, G. et al. The receptor S1P1 overrides regulatory $\mathrm{T}$ cell-mediated immune suppression through Akt-mTOR. Nat. Immunol. 10, 769-777 (2009)

168. Liu, G., Yang, K., Burns, S., Shrestha, S. \& Chi, H. The S1P1-mTOR axis directs the reciprocal differentiation of TH1 and Treg cells. Nat. Immunol. 11, 1047-1056 (2010).

169. Lai, Z. W. et al. N-Acetylcysteine reduces disease activity by blocking mammalian target of rapamycin in T cells from systemic lupus erythematosus patients: a randomized, double-blind, placebo-controlled trial. Arthritis Rheum. 64, 2937-2946 (2012)

170. Yin, Y. et al. Normalization of CD4 + T cell metabolism reverses lupus. Sci. Transl Med. 7, 274 ra18 (2015). This is one of the first studies to suggest that autoimmunity can be controlled through metabolism.

171. Hancock, W. W., Akimova, T., Beier, U. H., Liu, Y. \& Wang, L. HDAC inhibitor therapy in autoimmunity and transplantation. Ann. Rheum. Dis. 71 (Suppl. 2), i46-i54 (2012).

172. Regna, N. L. et al. Specific HDAC6 inhibition by ACY-738 reduces SLE pathogenesis in NZB/W mice. Clin. Immunol. 162, 58-73 (2016)

173. Zhang, Y. et al. Mice lacking histone deacetylase 6 have hyperacetylated tubulin but are viable and develop normally. Mol. Cell. Biol. 28, 1688-1701 (2008)

174. de Zoeten, E. F. et al. Histone deacetylase 6 and heat shock protein 90 control the functions of Foxp3 $(+)$ T-regulatory cells. Mol. Cell. Biol. 31, 2066-2078 (2011).

175. Fisson, S. et al. Continuous activation of autoreactive CD4 + CD25 + regulatory T cells in the steady state. J. Exp. Med. 198, 737-746 (2003)

176. Dawson, N. A. J. \& Levings, M. K. Antigen-specific regulatory T cells: are police CARs the answer? Trans/ Res. 187, 53-58 (2017)

177. Sadelain, M. CD19 CAR T cells. Cell 171, 1471 (2017)

178. Blat, D., Zigmond, E., Alteber, Z., Waks, T. \& Eshhar, Z. Suppression of murine colitis and its associated cancer by carcinoembryonic antigen-specific regulatory T cells. Mol. Ther. 22, 1018-1028 (2014).

179. MacDonald, K. G. et al. Alloantigen-specific regulatory $T$ cells generated with a chimeric antigen receptor J. Clin. Invest. 126, 1413-1424 (2016).

180. Boardman, D. A. et al. Expression of a chimeric antigen receptor specific for donor HLA class enhances the potency of human regulatory $T$ cells in preventing human skin transplant rejection. Am. J. Transplant. 17, 931-943 (2017).

181. Adair, P. R., Kim, Y. C., Zhang, A.-H., Yoon, J. \& Scott, D. W. Human Tregs made antigen specific by gene modification: the power to treat autoimmunity and antidrug antibodies with precision. Front. Immunol 8, 1117 (2017)

182. Rosenberg, S. A. et al. A progress report on the treatment of 157 patients with advanced cancer using lymphokine-activated killer cells and interleukin- 2 or high-dose interleukin-2 alone. N. Engl. J. Med. 316 , 889-897 (1987).

183. Yu, A. et al. Selective IL-2 responsiveness of regulatory T cells through multiple intrinsic mechanisms support the use of low-dose IL-2 therapy in type- 1 diabetes. Diabetes 64, 2172-2183 (2015)

184. Laurence, A. et al. Interleukin-2 signaling via STAT5 constrains T helper 17 cell generation. Immunity $\mathbf{2 6}$, 371-381 (2007)

185. Ballesteros-Tato, A. et al. Interleukin-2 inhibits germinal center formation by limiting $T$ follicular helper cell differentiation. Immunity 36, 847-856 (2012)

186. Gutierrez-Ramos, J. C., Andreu, J. L., Revilla, Y., Vinuela, E. \& Martinez, C. Recovery from autoimmunity of $\mathrm{MRL} / \mathrm{lpr}$ mice after infection with an interleukin-2/vaccinia recombinant virus. Nature 346 271-274 (1990)
187. Mizui, M et al. IL-2 protects lupus-prone mice from multiple end-organ damage by limiting CD4-CD8 IL-17-producing T cells. J. Immunol. 193, 2168-2177 (2014).

88. Sadlack, B. et al. Ulcerative colitis-like disease in mice with a disrupted interleukin-2 gene. Cell 75, 253-261 (1993).

189. Suzuki, H. et al. Deregulated T cell activation and autoimmunity in mice lacking interleukin-2 receptor beta. Science 268, 1472-1476 (1995).

190. Willerford, D. M. et al. Interleukin-2 receptor alpha chain regulates the size and content of the peripheral lymphoid compartment. Immunity 3, 521-530 (1995).

91. Malek, T. R., Yu, A., Vincek, V., Scibelli, P. \& Kong, L. $C D 4$ regulatory $T$ cells prevent lethal autoimmunity in IL-2R $\beta$-deficient mice: implications for the nonredundant function of IL-2. Immunity 17 , 167-178 (2002).

192. Lemoine, F. M. et al. Massive expansion of regulatory T cells following interleukin 2 treatment during a phase I-II dendritic cell-based immunotherapy of metastatic renal cancer. Int. J. Oncol. 35, 569-581 (2009).

193. Rosenberg, S. A. IL-2: the first effective immunotherapy for human cancer. J. Immunol. 192 5451-5458 (2014).

194. Saadoun, D. et al. Restoration of peripheral immune homeostasis after rituximab in mixed cryoglobulinemia vasculitis. Blood 111, 5334-5341 (2008).

195. Landau, D.-A. et al. Correlation of clinical and virologic responses to antiviral treatment and regulatory $\mathrm{T}$ cell evolution in patients with hepatitis $C$ virus-induced mixed cryoglobulinemia vasculitis. Arthritis Rheum. 58, 2897-2907 (2008)

196. Koreth, J. et al. Interleukin-2 and regulatory T cells in graft-versus-host disease. N. Engl. J. Med. 365, 2055-2066 (2011)

This is the first study to show that low-dose IL-2 has clinical benefit in patients with GVHD linked to the expansion of $T_{\text {reg }}$ cells.

197. Kennedy-Nasser, A. A. et al. Ultra low-dose IL-2 for GVHD prophylaxis after allogeneic hematopoietic stem cell transplantation mediates expansion of regulatory $\mathrm{T}$ cells without diminishing antiviral and antileukemic activity. Clin. Cancer Res. 20, 2215-2225 (2014)

198. Castela, E. et al. Effects of low-dose recombinant interleukin 2 to promote T-regulatory cells in alopecia areata. JAMA Dermatol 150, 748-751 (2014).

199. Humrich, J. Y. et al. A3.11 Induction of remission by low-dose IL-2-therapy in one SLE patient with increased disease activity refractory to standard therapies: a case report. Ann. Rheum. Dis. 73, A46 (2014).

200. von Spee-Mayer, C. et al. Low-dose interleukin-2 selectively corrects regulatory $\mathrm{T}$ cell defects in patients with systemic lupus erythematosus. Ann. Rheum. Dis. 75, 1407-1415 (2015)

201. He, J et al. Low-dose interleukin-2 treatment selectively modulates CD4(+) T cell subsets in patients with systemic lupus erythematosus. Nat. Med. 22, 991-993 (2016).

202. Moulton, V. R. et al. Pathogenesis of human systemic lupus erythematosus: a cellular perspective. Trends Mol. Med. 23, 615-635 (2017)

203. Hartemann, A. et al. Low-dose interleukin 2 in patients with type 1 diabetes: a phase $1 / 2$ randomised, double-blind, placebo-controlled trial. Lancet Diabetes Endocrinol. 1, 295-305 (2013).

204. Mitra, S. et al. Interleukin-2 activity can be fine tuned with engineered receptor signaling clamps. Immunity 42, 826-838 (2015)

205. Goodson, R. J. \& Katre, N. V. Site-directed pegylation of recombinant interleukin-2 at its glycosylation site. Biotechnology 8, 343-346 (1990).

206. Bell, C. J. M. et al. Sustained in vivo signaling by longlived IL-2 induces prolonged increases of regulatory T cells. J. Autoimmun. 56, 66-80 (2015).

207. Yeh, P. et al. Design of yeast-secreted albumin derivatives for human therapy: biological and antiviral properties of a serum albumin-CD4 genetic conjugate. Proc. Natl Acad. Sci. USA 89, 1904-1908 (1992).

208. Yao, Z., Dai, W., Perry, J., Brechbiel, M. W. \& Sung, C. Effect of albumin fusion on the biodistribution of interleukin-2. Cancer Immunol. Immunother. 53, 404-410 (2004)

209. Boyman, O., Kovar, M., Rubinstein, M. P., Surh, C. D. \& Sprent, J. Selective stimulation of T cell subsets with antibody-cytokine immune complexes. Science $\mathbf{3 1 1}$ 1924-1927 (2006). 
210. Arenas-Ramirez, N. et al. Improved cancer immunotherapy by a CD25-mimobody conferring selectivity to human interleukin-2. Sci. Transl Med. 8 367ra166 (2016).

211. Trotta, E. et al. A human anti-IL-2 antibody that potentiates regulatory T cells by a structure-based mechanism. Nat. Med. 24, 1005-1014 (2018). This study shows that a fully human anti-IL-2 antibody stabilizes IL-2 in a conformation that results in the preferential STAT5 phosphorylation of $T_{\text {reg }}$ cells in vitro and their selective expansion in vivo to mitigate experimental diabetes and multiple sclerosis.

212. Mahnke, K. et al. The dendritic cell receptor for endocytosis, DEC-205, can recycle and enhance antigen presentation via major histocompatibility complex class II-positive lysosomal compartments. J. Cell Biol. 151, 673-684 (2000).

213. Polansky, J. K. et al. DNA methylation controls Foxp3 gene expression. Eur. J. Immunol. 38, 1654-1663 (2008).

214. Bruder, D. et al. On the edge of autoimmunity: T cell stimulation by steady-state dendritic cells prevents autoimmune diabetes. Diabetes 54, 3395-3401 (2005).

215. Hawiger, D., Masilamani, R. F., Bettelli, E. Kuchroo, V. K. \& Nussenzweig, M. C. Immunological unresponsiveness characterized by increased expression of $\mathrm{CD} 5$ on peripheral T cells induced by dendritic cells in vivo. Immunity 20, 695-705 (2004)

216. Raker, V. K., Domogalla, M. P. \& Steinbrink, K Tolerogenic dendritic cells for regulatory $T$ cell induction in man. Front. Immunol. 6, 569 (2015).

217. Benham, H. et al. Citrullinated peptide dendritic cell immunotherapy in HLA risk genotype-positive rheumatoid arthritis patients. Sci. Transl Med. 7 290 ra87 (2015)

218. Johnson, K. P. et al. Copolymer 1 reduces relapse rate and improves disability in relapsing-remitting multiple sclerosis: results of a phase III multicenter, doubleblind, placebo-controlled trial. 1995. Neurology 57, S16-S24 (2001)

219. Jee, Y. et al. CD4(+)CD25(+) regulatory T cells contribute to the therapeutic effects of glatiramer acetate in experimental autoimmune encephalomyelitis. Clin. Immunol. 125, 34-42 (2007).

220. Sharabi, A., Zinger, H., Zborowsky, M., Sthoeger, Z. M. $\&$ Mozes, E. A peptide based on the complementaritydetermining region 1 of an autoantibody ameliorates lupus by up-regulating CD4 + CD25 + cells and TGFbeta. Proc. Natl Acad. Sci. USA 103, 8810-8815 (2006).

221. Sthoeger, Z. M. et al. Treatment of lupus patients with a tolerogenic peptide, hCDR1 (Edratide): immunomodulation of gene expression. J. Autoimmun 33, 77-82 (2009).

222. Sharabi, A., Lapter, S. \& Mozes, E. Bcl-xL is required for the development of functional regulatory CD4 cells in lupus-afflicted mice following treatment with a tolerogenic peptide. J. Autoimmun. 34, 87-95 (2010).

223. Sharabi, A. \& Mozes, E. The suppression of murine lupus by a tolerogenic peptide involves foxp3-expressing CD8 cells that are required for the optimal induction and function of foxp3-expressing CD4 cells. J. Immunol. 181, 3243-3251 (2008).

224. Urowitz, M. B., Isenberg, D. A. \& Wallace, D. J. Safety and efficacy of hCDR1 (Edratide) in patients with active systemic lupus erythematosus: results of phase II study. Lupus Sci. Med. 2, e000104 (2015)

225. Kang, H. K., Michaels, M. A., Berner, B. R. $\delta$ Datta, S. K. Very low-dose tolerance with nucleosomal peptides controls lupus and induces potent regulatory T cell subsets. J. Immunol. 174 3247-3255 (2005)

226. Hahn, B. H., Singh, R. P., La Cava, A. \& Ebling, F. M Tolerogenic treatment of lupus mice with consensus peptide induces Foxp3-expressing, apoptosisresistant, TGFbeta-secreting CD8 + T cell suppressors. J. Immunol. 175, 7728-7737 (2005).

227. Leavenworth, J. W., Wang, X., Wenander, C. S. Spee, P. \& Cantor, H. Mobilization of natural killer cells inhibits development of collagen-induced arthritis. Proc. Natl Acad. Sci. USA 108 14584-14589 (2011)

228. Gertel, S., Serre, G., Shoenfeld, Y. \& Amital, H. Immune tolerance induction with multiepitope peptide derived from citrullinated autoantigens attenuates arthritis manifestations in adjuvant arthritis rats. J. Immunol. 194, 5674-5680 (2015).
229. Deshmukh, U. S., Bagavant, H., Lewis, J., Gaskin, F. \& Fu, S. M. Epitope spreading within lupus-associated ribonucleoprotein antigens. Clin. Immunol. 117, 112-120 (2005).

230. Herrath, J. et al. The inflammatory milieu in the rheumatic joint reduces regulatory $T$ cell function. Eur. J. Immunol. 41, 2279-2290 (2011).

231. Vargas-Rojas, M. I., Crispin, J. C., Richaud-Patin, Y. \& Alcocer-Varela, J. Quantitative and qualitative normal regulatory $\mathrm{T}$ cells are not capable of inducing suppression in SLE patients due to T cell resistance. Lupus 17, 289-294 (2008).

232. Ghiringhelli, F. et al. Metronomic cyclophosphamide regimen selectively depletes $C D 4+C D 25+$ regulatory $\mathrm{T}$ cells and restores $\mathrm{T}$ and NK effector functions in end stage cancer patients. Cancer Immunol. Immunother. 56, 641-648 (2007).

233. Lutsiak, M. E. et al. Inhibition of CD4(+)25+ $T$ regulatory cell function implicated in enhanced immune response by low-dose cyclophosphamide. Blood 105, 2862-2868 (2005)

234. Ge, Y. et al. Metronomic cyclophosphamide treatment in metastasized breast cancer patients: immunological effects and clinical outcome. Cancer Immunol. Immunother. 61, 353-362 (2012).

235. Adotevi, O. et al. A decrease of regulatory T cells correlates with overall survival after sunitinib-based antiangiogenic therapy in metastatic renal cancer patients. J. Immunother. 33, 991-998 (2010).

236. Desar, I. M. et al. Sorafenib reduces the percentage of tumour infiltrating regulatory $\mathrm{T}$ cells in renal cell carcinoma patients. Int. J. Cancer 129, 507-512 (2011).

237. Coussens, L. M. \& Werb, Z. Inflammation and cancer Nature 420, 860-867 (2002).

238. Curiel, T. J. et al. Specific recruitment of regulatory T cells in ovarian carcinoma fosters immune privilege and predicts reduced survival. Nat. Med. 10 , 942-949 (2004).

239. Chang, D. K. et al. Anti-CCR4 monoclonal antibody enhances antitumor immunity by modulating tumorinfiltrating Tregs in an ovarian cancer xenograft humanized mouse model. Oncoimmunology 5, e1090075 (2016)

240. Ogura, M et al. Multicenter phase II study of mogamulizumab (KW-0761), a defucosylated anti-cc chemokine receptor 4 antibody, in patients with relapsed peripheral T cell lymphoma and cutaneous T cell lymphoma. J. Clin. Oncol. 32, 1157-1163 (2014)

241. Ishida, T. et al. Mogamulizumab for relapsed adult T cell leukemia-lymphoma: updated follow-up analysis of phase I and II studies. Cancer Sci. 108, 2022-2029 (2017).

242. Ifuku, H. et al. Fatal reactivation of hepatitis B virus infection in a patient with adult $\mathrm{T}$ cell leukemialymphoma receiving the anti-CC chemokine receptor 4 antibody mogamulizumab. Hepatol. Res. 45 1363-1367 (2015)

243. Kurose, K. et al. Phase la study of FoxP3 + CD4 Treg depletion by infusion of a humanized anti-CCR4 antibody, KW-0761, in cancer patients. Clin. Cancer Res. 21, 4327-4336 (2015).

244. De Simone, M. et al. Transcriptional landscape of human tissue lymphocytes unveils uniqueness of tumorinfiltrating T regulatory cells. Immunity 45, 1135-1147 (2016)

245. Attia, P. et al. Selective elimination of human regulatory T lymphocytes in vitro with the recombinant immunotoxin LMB-2. J Immunother 29, 208-214 (2006).

246. Rech, A. J. et al. CD25 blockade depletes and selectively reprograms regulatory T cells in concert with immunotherapy in cancer patients. Sci. Trans/ Med. 4 $134 \mathrm{ra62}$ (2012)

247. Kreitman R J et al. Phase I trial of recombinant immunotoxin anti-Tac(Fv)-PE38 (LMB-2) in patients with hematologic malignancies. J. Clin. Oncol. 18 1622-1636 (2000)

248. Kreitman, R. J. et al. Complete remissions of adult T cell leukemia with anti-CD25 recombinant immunotoxin LMB-2 and chemotherapy to block immunogenicity. Clin. Cancer Res. 22, 310-318 (2016).

249. Powell, D. J. Jr. et al. Administration of a CD25-directed immunotoxin, LMB-2, to patients with metastatic melanoma induces a selective partial reduction in regulatory T cells in vivo. J. Immunol. 179, 4919-4928 (2007)

250. Dannull, J. et al. Enhancement of vaccine-mediated antitumor immunity in cancer patients after depletion of regulatory T cells. J. Clin. Invest. 115, 3623-3633 (2005).
251. Attia, P., Maker, A. V., Haworth, L. R., RogersFreezer, L. \& Rosenberg, S. A. Inability of a fusion protein of IL-2 and diphtheria toxin (Denileukin Diftitox, DAB389IL-2, ONTAK) to eliminate regulatory T lymphocytes in patients with melanoma. J. Immunother. 28, 582-592 (2005).

252. Maury, S. et al. Lymphodepletion followed by infusion of suicide gene-transduced donor lymphocytes to safely enhance their antitumor effect: a phase $\mathrm{I} / \mathrm{II}$ study. Leukemia 28, 2406-2410 (2014).

253. Attia, P. et al. Autoimmunity correlates with tumor regression in patients with metastatic melanoma treated with anti-cytotoxic T-lymphocyte antigen-4. J. Clin. Oncol. 23, 6043-6053 (2005).

254. Hodi, F. S. et al. Improved survival with ipilimumab in patients with metastatic melanoma. N. Engl. J. Med. 363, 711-723 (2010).

255. Robert, C. et al. Ipilimumab plus dacarbazine for previously untreated metastatic melanoma. N. Engl. J. Med. 364, 2517-2526 (2011)

256. Simpson, T. R. et al. Fc-dependent depletion of tumorinfiltrating regulatory $T$ cells co-defines the efficacy of anti-CTLA-4 therapy against melanoma. J. Exp. Med. 210, 1695-1710 (2013).

257. Peggs, K. S., Quezada, S. A., Chambers, C. A., Korman, A. J. \& Allison, J. P. Blockade of CTLA-4 on both effector and regulatory $\mathrm{T}$ cell compartments contributes to the antitumor activity of anti-CTLA-4 antibodies. J. Exp. Med. 206, 1717-1725 (2009)

258. Paterson, A. M. et al. Deletion of CTLA-4 on regulatory $T$ cells during adulthood leads to resistance to autoimmunity. J. Exp. Med. 212, 1603-1621 (2015).

259. Phan, G. Q. et al. Cancer regression and autoimmunity induced by cytotoxic T lymphocyte-associated antigen 4 blockade in patients with metastatic melanoma. Proc. Natl Acad. Sci. USA 100, 8372-8377 (2003).

260. Hodi, F. S. et al. Combined nivolumab and ipilimumab versus ipilimumab alone in patients with advanced melanoma: 2-year overall survival outcomes in a multicentre, randomised, controlled, phase 2 trial. Lancet Oncol. 17, 1558-1568 (2016).

261. Zhao, H., Liao, X. \& Kang, Y. Tregs: where we are and what comes next? Front. Immunol. 8, 1578 (2017).

262. Sasidharan Nair, V. \& Elkord, E. Immune checkpoint inhibitors in cancer therapy: a focus on T-regulatory cells. Immunol. Cell Biol. 96, 21-33 (2018).

263. Sabatos, C. A. et al. Interaction of Tim-3 and Tim-3 ligand regulates T helper type 1 responses and induction of peripheral tolerance. Nat. Immunol. $\mathbf{4}$, 1102-1110 (2003)

264. Coe, D. et al. Depletion of regulatory T cells by antiGITR mAb as a novel mechanism for cancer immunotherapy. Cancer Immunol. Immunother. 59 1367-1377 (2010).

265. Cohen, A. D. et al. Agonist anti-GITR monoclonal antibody induces melanoma tumor immunity in mice by altering regulatory $\mathrm{T}$ cell stability and intra-tumor accumulation. PLOS ONE 5, e10436 (2010).

266. Schaer, D. A., Murphy, J. T. \& Wolchok, J. D. Modulation of GITR for cancer immunotherapy. Curr. Opin. Immunol. 24, 217-224 (2012).

267. Schaer, D. A. et al. GITR pathway activation abrogates tumor immune suppression through loss of regulatory $\mathrm{T}$ cell lineage stability. Cancer Immunol. Res. 1, 320-331 (2013).

268. Ko, K. et al. Treatment of advanced tumors with agonistic anti-GITR mAb and its effects on tumorinfiltrating Foxp3 + CD25 + CD4 + regulatory T cells. J. Exp. Med. 202, 885-891 (2005).

269. Lu, L et al. Combined PD-1 blockade and GITR triggering induce a potent antitumor immunity in murine cancer models and synergizes with chemotherapeutic drugs. J. Transl Med. 12, 36 (2014).

270. Shimizu, J., Yamazaki, S., Takahashi, T., Ishida, Y. \& Sakaguchi, S. Stimulation of CD25(+)CD4(+) regulatory T cells through GITR breaks immunological self-tolerance. Nat. Immunol. 3, 135-142 (2002)

271. Murphy, J. T. et al. Anaphylaxis caused by repetitive doses of a GITR agonist monoclonal antibody in mice. Blood 123, 2172-2180 (2014).

272. Nakagawa, H. et al. Instability of Helios-deficient Tregs is associated with conversion to a T-effector phenotype and enhanced antitumor immunity. Proc. Natl Acad. Sci. USA 113, 6248-6253 (2016).

273. Ephrem, A. et al. Modulation of Treg cells/T effector function by GITR signaling is context-dependent. Eur. J. Immunol. 43, 2421-2429 (2013).

274. Liao, G. et al. GITR engagement preferentially enhances proliferation of functionally competent CD4 + CD25 + FoxP3 + regulatory T cells Int. Immunol. 22, 259-270 (2010). 
275. Curti, B. D. et al. OX40 is a potent immunestimulating target in late-stage cancer patients. Cancer Res. 73, 7189-7198 (2013).

276. Sturgill, E. R. \& Redmond, W. L. TNFR agonists: a review of current biologics targeting OX40, 4-1BB, CD27, and GITR. Am. J. Hematol. Oncol. 13, 4-15 (2017).

277. Lesokhin, A. M., Callahan, M. K., Postow, M. A. $\delta$ Wolchok, J. D. On being less tolerant: enhanced cancer immunosurveillance enabled by targeting checkpoints and agonists of T cell activation. Sci. Transl Med. 7, 280sr 1 (2015).

278. Knee, D. A., Hewes, B. \& Brogdon, J. L. Rationale for anti-GITR cancer immunotherapy. Eur. J. Cancer 67, $1-10(2016)$

279. Torrey, $\mathrm{H}$. et al. Targeting TNFR2 with antagonistic antibodies inhibits proliferation of ovarian cancer cells and tumor-associated Tregs. Sci. Signal. 10, eaaf8608 (2017).

280. Faustman, D. \& Davis, M. TNF receptor 2 pathway: drug target for autoimmune diseases. Nat. Rev. Drug Discov. 9, 482-493 (2010)

281. He, X. et al. A TNFR2-agonist facilitates high purity expansion of human low purity Treg cells. PLOS ONE 11, e0156311 (2016)

282. Okubo, Y., Mera, T., Wang, L. \& Faustman, D. L. Homogeneous expansion of human T-regulatory cells via tumor necrosis factor receptor 2. Sci. Rep. 3, 3153 (2013)

283. Chopra, M. et al. Exogenous TNFR2 activation protects from acute GvHD via host T reg cell expansion. J. Exp. Med. 213, 1881-1900 (2016).

284. Fallarino, F. et al. Modulation of tryptophan catabolism by regulatory T cells. Nat. Immunol. 4, 1206-1212 (2003).

285. Fallarino, F. et al. The combined effects of tryptophan starvation and tryptophan catabolites down-regulate $T$ cell receptor zeta-chain and induce a regulatory phenotype in naive T cells. J. Immunol. 176, 6752-6761 (2006)

286. Prendergast, G. C., Malachowski, W. P., DuHadaway, J. B. \& Muller, A. J. Discovery of IDO 1 inhibitors: from bench to bedside. Cancer Res. 77, 6795-6811 (2017)

287. Vacchelli, E. et al. Trial watch: IDO inhibitors in cancer therapy. Oncoimmunology 3, e957994 (2014).

288. Sharma, M. D. et al. Indoleamine 2,3-dioxygenase controls conversion of Foxp3 + Tregs to TH17-like cells in tumor-draining lymph nodes. Blood 113 , 6102-6111 (2009).

289. Soares, K. C. et al. TGF- $\beta$ blockade depletes $T$ regulatory cells from metastatic pancreatic tumors in a vaccine dependent manner. Oncotarget 6 , 43005-43015 (2015)

290. Turnis, M. E. et al. Interleukin-35 limits anti-tumor immunity. Immunity 44, 316-329 (2016).

291. Yu, P. et al. Intratumor depletion of CD4 + cells unmasks tumor immunogenicity leading to the rejection of late-stage tumors. J. Exp. Med. 201 779-791 (2005)

292. Lu, J. et al. Increased expression of neuropilin 1 in melanoma progression and its prognostic significance in patients with melanoma. Mol. Med. Rep. 12 2668-2676 (2015).

293. Overacre-Delgoffe, A. E. et al. Interferon- $\gamma$ drives Treg fragility to promote anti-tumor immunity. Cell 169, 1130-1141 (2017)
This paper shows that NRP1 is required to maintain intratumoural $\mathrm{T}_{\text {reg }}$ stability and function and that NRP1-deficient $T_{\text {reg }}$ cells produce IFN $\gamma$, which promotes $\mathrm{T}_{\text {reg }}$ cell fragility and boosts antitumour activity.

294. Grinberg-Bleyer, Y. et al. IL-2 reverses established type 1 diabetes in NOD mice by a local effect on pancreatic regulatory T cells. J. Exp. Med. 207, 1871-1878 (2010)

295. Clever, D. et al. Oxygen sensing by T cells establishes an immunologically tolerant metastatic niche. Cell 166 1117-1131 (2016)

This is a novel study that explains the abundance of lung metastases by various tumours. Low oxygen pressure promotes the development of $\mathbf{T}_{\text {reg }}$ cells, which promote tumour growth.

296. Chen, P. L. et al. Analysis of immune signatures in longitudinal tumor samples yields insight into biomarkers of response and mechanisms of resistance to immune checkpoint blockade. Cancer Discov. 6 , 827-837 (2016).

297. Linsley, P. S., Chaussabel, D. \& Speake, C. The relationship of immune cell signatures to patient survival varies within and between tumor types. PLOS ONE 10, e0138726 (2015)

298. Kitagawa, Y. et al. Guidance of regulatory T cell development by Satb 1-dependent super-enhancer establishment. Nat. Immunol. 18, 173-183 (2017). This study introduces the concept that super-enhancers can be modulated to dictate cell lineage differentiation.

299. Zhou, X., Tang, J., Cao, H., Fan, H. \& Li, B. Tissue resident regulatory $\mathrm{T}$ cells: novel therapeutic targets for human disease. Cell. Mol. Immunol. 12, 543-552 (2015).

300. Hovhannisyan, Z., Treatman, J., Littman, D. R. \& Mayer, L. Characterization of interleukin-17-producing regulatory $\mathrm{T}$ cells in inflamed intestinal mucosa from patients with inflammatory bowel diseases. Gastroenterology 140, 957-965 (2011).

301. Cipolletta, D. et al. PPAR-gamma is a major driver of the accumulation and phenotype of adipose tissue Treg cells. Nature 486, 549-553 (2012).

This study shows that $T_{\text {reg }}$ cells that infiltrate tissues and become tissue-resident $T$ cells express transcription factors that are master regulators of the specific tissue. PPAR $\gamma$ is a master regulator of adipose tissue.

302. Feuerer, M. et al. Lean, but not obese, fat is enriched for a unique population of regulatory $T$ cells that affect metabolic parameters. Nat. Med. 15, 930-939 (2009).

303. Vasanthakumar, A. et al. The transcriptional regulators IRF4, BATF and IL-33 orchestrate development and maintenance of adipose tissue-resident regulatory T cells. Nat. Immunol. 16, 276-285 (2015).

304. Atarashi, K. et al. Treg induction by a rationally selected mixture of Clostridia strains from the human microbiota. Nature 500, 232-236 (2013).

305. Malhotra, N. et al. RORa-expressing T regulatory cells restrain allergic skin inflammation. Sci. Immunol. 3 eaao6923 (2018).

This study shows that expression of retinoid-related orphan receptor- $\alpha(R O R \alpha)$ in skin-resident $T_{\text {, }}$ cells is important for restraining allergic skin inflammation.

306. Pesenacker, A. M., Broady, R. \& Levings, M. K. Control of tissue-localized immune responses by human regulatory T cells. Eur. J. Immunol. 45, 333-343 (2015).

307. Akimova, T. et al. Human lung tumor FOXP3 + Tregs upregulate four "Treg-locking" transcription factors. JCl Insight 2, 94075 (2017)
308. Burzyn, D. et al. A special population of regulatory T cells potentiates muscle repair. Cell 155, 1282-1295 (2013).

This study introduces the concept that $\mathbf{T}_{\text {reg }}$ cells can participate in the repair of injured tissue through the factors they produce. $T_{\text {reg }}$ cells repair injured muscle through the production of amphiregulin.

309. Arpaia, N. et al. A distinct function of regulatory T cells in tissue protection. Cell 162, 1078-1089 (2015).

310. Zaiss, D. M. et al. Amphiregulin enhances regulatory $\mathrm{T}$ cell-suppressive function via the epidermal growth factor receptor. Immunity 38, 275-284 (2013).

311. Sanchez Rodriguez, R. et al. Memory regulatory T cells reside in human skin. J. Clin. Invest. 124, 1027-1036 (2014)

312. Nosbaum, A. et al. Cutting edge: regulatory T cells facilitate cutaneous wound healing. J. Immunol. 196, 2010-2014 (2016)

313. Ali, N. et al. Regulatory T cells in skin facilitate epithelial stem cell differentiation. Cell 169 1119-1129 (2017).

This study provides another example of $\mathrm{T}_{\text {reg }}$ cells being involved in tissue repair and/or regeneration. Skin-resident $\mathrm{T}_{\text {reg }}$ cells were found to express preferentially high levels of the NOTCH ligand family member jagged 1 , which promoted the function of skin stem cells

314. Zacchigna, S. et al. Paracrine effect of regulatory T cells promotes cardiomyocyte proliferation during pregnancy and after myocardial infarction. Nat. Commun. 9, 2432 (2018).

315. Bieber, A. J., Kerr, S. \& Rodriguez, M. Efficient central nervous system remyelination requires T cells. Ann. Neurol. 53, 680-684 (2003).

316. Dombrowski, Y. et al. Regulatory T cells promote myelin regeneration in the central nervous system. Nat. Neurosci. 20, 674-680 (2017).

Acknowledgements

The authors' work was supported by US National Institutes of Health (NIH) grants Al42269, R37Al49954, Al068787, Al085567 and AR064350 (G.C.T.) and R21-CA195334 R01-AI131648 and the Sylvester Comprehensive Cancer Center at the University of Miami (T.R.M.)

\section{Competing interest}

G.C.T. is a consultant for Johnson $\&$ Johnson and a science advisory board member for Abpro and Silicon Therapeutics (appointments that are not related to the work discussed herein). D.K. is an inventor on a patent application claiming low-dose IL-2 for therapy of autoimmune diseases, which is owned by his academic institution and licensed to ILTOO Pharma; D.K. advises for and holds shares in ILTOO Pharma. The University of Miami and T.R.M. have a patent pending WO2016022671A1) on IL-2/CD25 fusion proteins that has been licensed exclusively to Bristol-Myers Squibb and have a collaboration and sponsored research $\&$ licensing agreement with Bristol-Myers Squibb. A.S., M.G.T. and Y.D. declare no competing interests.

Supplementary information

Supplementary information is available for this paper at https://doi.org/10.1038/nrd.2108.48. 